\title{
La Reconceptualización: una opción a la encrucijada del Trabajo Social en Colombia
}

\section{Reconceptualization: an Option to the Crossroads of Social Work in Colombia}

\author{
Víctor Mario Estrada-Ospina \\ Trabajador Social. Magíster en Estudios Políticos \\ Universidad del Valle. Cali, Colombia \\ victor.estrada@correounivalle.edu.co
}

\section{A manera de introducción}

El énfasis en esta publicación no está centrado en el análisis del cuestionamiento sobre la profesión llevado a cabo por la "Generación del 65", en cuanto a su filosofía, fundamentos teórico-conceptuales, fines, objetivos y los denominados métodos tradicionales o clásicos. Por el contrario, se pretende más bien profundizar en el análisis de la experiencia colombiana, realizada por una de las unidades académicas pioneras de la Reconceptualización, como condición fundamental que permita examinar si las tesis que en ese momento se planteaban estaban en correspondencia con el carácter complejo de la realidad social. De otro lado, porque sólo a partir de ese análisis se podría avanzar en la construcción de un marco referencial teórico-metodológico más aproximado, cuando se asistía a un momento histórico en el que el Trabajo Social como profesión, luchaba en la búsqueda y elaboración de alternativas que respondieran ampliamente a la realidad social latinoamericana (perspectiva y proceso que aún hoy sigue teniendo vigencia), que le permitiera avanzar, superando el dilema o la encrucijada en que se encontraba.

Este proceso de cuestionamiento profesional tiene explicación en un contexto caracterizado por el "agotamiento" o "crisis" del modelo económico de desarrollo capitalista, que se venía promoviendo en el continente por los centros hegemónicos de poder internacional, a partir de la conmoción conocida como la "Gran Crisis o Depresión Económica Mundial", que se inició en 1929 y cuyos efectos económicos, políticos, sociales se manifestaron hasta 1936. Después de un relativo auge en el proceso de industrialización en algunos países, con un tipo de capitalismo dependiente, este modelo económico de desarrollo hacia adentro, en la década de 1950 empezó a manifestar los primeros signos de "agotamiento", lo cual se expresa en la imposibilidad de vincular laboralmente a la

Esta obra está bajo una Licencia Creative Commons Atribución-NoComercial-CompartirIgual 4.0 Internacional.

¿Cómo citar este artículo? / How to quote this article?

Estrada-Ospina, V.M. (2020). La Reconceptualización: una opción a la encrucijada del Trabajo Social en Colombia. Prospectiva. Revista de Trabajo Social e intervención social, (29), 01-38. doi: 10.25100/prts.v0i29.8097. 
población a las actividades productivas, la existencia de un desempleo estructural, el aumento de la pobreza y la situación de injusticia social generalizada. Desde entonces, se inicia y profundiza un debate en el continente latinoamericano en torno a los llamados "obstáculos para el desarrollo", la situación de subdesarrollo y de dependencia de estos países en el ámbito internacional. ${ }^{1}$ Este es el contexto en el que surge el movimiento de Reconceptualización signado por la crisis y la perspectiva política que se debatía en esa época en todo el continente, "Reforma o Revolución".

Herman Kruse (1969) uno de los más sobresalientes miembros de la “Generación del 65 ", refiriéndose al problema de la encrucijada en que se encontraba el Servicio Social en ese momento 2 , formulaba el siguiente planteamiento: “Uno de los clásicos de la literatura uruguaya, el "Tabaré" de Zorrilla de San Martín, comienza en estos versos: “El Paraná y el plata vivían su salvaje primavera $(. . .)^{\prime \prime}$. El poeta necesitó apenas nueve palabras para definir

${ }^{1}$ Es clave anotar que este debate toma mucha fuerza en este período en el ámbito continental, el cual se fortalece en la medida en que los teóricos de la dependencia fundamentando sus teorías en investigaciones concretas, comienzan a elaborar desde una perspectiva genuinamente Latinoamericana, explicaciones sobre la razón de ser del subdesarrollo de estas economías. Se deben destacar algunos autores como: André Gunder-Frank, 1967, 1973; Celso Furtado, 1969 y otros como: Theotonio dos Santos, Fernando H. Cardoso. Alonso Aguilar, Josué de Castro y a los colombianos Mario Arrubla con su texto clásico: "Ensayos sobre el Subdesarrollo Colombiano" y José Consuegra Higgins con su original "Teoría de la dependencia y el subdesarrollo estructural"; este último fue además, fundador de la "Revista Desarrollo Indoamericano" en 1966 y fundador también de la Universidad Simón Bolívar de Barranquilla en 1973. Por último, hay que destacar los debates que se iniciaron con la Escuela Cepalina bajo la dirección de Raúl Prebisch y los aportes a esta reflexión de entidades como la CEPAL (Comisión Económica para América Latina) fundada en 1948 y su organismo adscrito el ILPES (Instituto Latinoamericano de Planificación Económica y Social) creado en 1962.

2 Desde el punto de vista histórico es importante destacar la conferencia dictada por Kruse en Concepción Chile en 1969 por este importante miembro de la "Generación del 65". Sobre el particular señalaba el autor: "La primera oportunidad de expresar públicamente estas nuevas ideas sobre la profesión en el Cono Sur, la brindaron los colegas brasileños al organizar en Porto Alegre en mayo de 1965, el I Seminario Regional Latinoamericano de Servicio Social. A partir de ese encuentro empezamos a llamar la "Generación del 65" al grupo de profesionales de los tres países sur-atlánticos (Brasil, Uruguay y Argentina) del continente que compartían esas inquietudes; paralelamente aparecía en Buenos Aires, el No 1 de la Revista "Hoy en el Servicio Social", (posteriormente cambió su nombre siendo conocida ahora como "Hoy en el Trabajo Social"), esta publicación fue editada por la Editorial ECRO). Kruse (1969) en ese momento comentaba: la "Generación del 65" es gente que oscila entre los 35 y 45 años de edad, que pasó por la Escuela de Servicio Social en la década del 50 recibiendo el pleno impacto del servicio social al estilo norteamericano y entró luego a trabajar en las viejas instituciones acumulando razonamientos y frustraciones. Es la generación que se puso a repensar el servicio social, sin desdeñar la formación científica, pero sopesando la realidad institucional y el marco global de subdesarrollo en medio del cual se debía actuar (...) Aunque dicho sea de paso, su lucha generacional es muy distinta en las instituciones, que en los centros docentes, porque en la primeras sus arquetipos se confrontan con los de una generación mayor, en retirada, superada por el cambio social vertiginoso y temerosa; en tanto que en las Universidades, sus arquetipos se confrontan con los de una generación menor, virgen de fracasos, pujante, con sed de llegar a ser y mucho más definida ideológicamente." A nivel continental, el documento más representativo de la nueva concepción del servicio social, sin lugar a dudas, fue el Informe de Araxá del año 1967 (Kusse, 1969, p. 1-2).

Prospectiva. Revista de Trabajo Social e intervención social • No. $29 \bullet$ ene.-jun. $2020 \bullet$ pp. 01-38 e-ISSN: 2389-993X • Doi: 10.25100/prts.v0i29.8097 Universidad del Valle - Cali, Colombia 
el mundo sereno, idílico, que la llegada del español terminaría para siempre. Si tuviéramos que definir el Servicio Social de hace una década, tendríamos que buscar términos parecidos a los que usó Zorrilla de San Martin, porque nuestra profesión vivía una dorada y plácida adolescencia. Ese devenir idílico hoy se ha quebrantado. Nuestra profesión vive intensamente una problemática compleja. Podríamos decir en el sentido unamuniano del término, que el Servicio Social agoniza, o sea, lucha por sobrevivir. Creemos que el Servicio Social se enfrenta a una encrucijada. Y la Enciclopedia nos dice que encrucijada es "punto de intersección de dos o más calles o caminos (...) alternativa, dilema." ¿Qué es lo que nos ha colocado en la encrucijada? Nos atrevemos a decir que dos fuertes impactos que ha recibido la profesión en la presente década: un impacto generacional y un impacto ideológico" (Kruse, 1969, p. 1).

A partir de este fuerte impacto generacional e ideológico empezaron a soplar nuevos vientos desde el Cono Sur hacia el Norte de Suramérica, lo cual permitió que fueran circulando con notable fuerza sus principales ideas y propuestas. Este cuestionamiento, el planteamiento de diferentes posturas ideológico-políticas y teóricas, en relación con la formación académica, se convirtió en la base para reorientar algunos programas de Trabajo Social en Colombia, en particular el programa de estudios de Trabajo Social de la Universidad de Caldas, el cual se constituyó en el más importante abanderado de este movimiento, contando para ese entonces con una nueva estructura curricular que incorporó las principales ideas que se venían reconceptualizando ${ }^{3}$.

En ese contexto se abre el programa académico vinculándose la primera promoción de estudiantes admitidos directamente por la Universidad, se promueve un nuevo currículo y la realización de unas prácticas académicas desde los primeros semestres. Al comienzo ligada a instituciones públicas y privadas; luego por fuera de ellas, por supuesto, sin hacer una crítica fundamentada sobre el rol o papel de estas entidades, sobre todo de aquellas encargadas del tema social; a nombre de una perspectiva crítica se las rechazó por razones puramente ideológico-políticas, puesto que se conceptuaban desde una mirada simplista por determinista y mecanicista, como instrumentos de dominación para el mantenimiento del orden político, social. Era como si al abandonar las instituciones la dominación despareciera o se neutralizara; esta posición se puede calificar como una postura bastante ingenua desde el punto de vista ideológico-político.

${ }^{3}$ La Facultad de Trabajo social fue creada en la Universidad de Caldas por decisión del Consejo Superior mediante el acta $\mathrm{N}^{\circ} 003$ del 11 de diciembre de 1967. El programa académico de estudios en Trabajo social fue creado primero por el Consejo Directivo y luego ratificado por el Consejo Superior según el acta Nº 007 del 4 de noviembre de 1968. El Consejo Directivo orienta iniciar actividades académicas admitiendo la primera promoción en 1969, efectivamente se da la admisión ese mismo año con un cupo de 100 estudiantes. Sin embargo, hay que precisar que creada la Facultad de Trabajo Social se recibió la última promoción de estudiantes que terminó estudios en el Colegio Católico femenino, las cuales se matricularon en 1968, durante un semestre en la Universidad de Caldas, graduándose posteriormente como Licenciadas en Trabajo Social; por esta razón, se les puede considerar como la primera cohorte de egresadas del programa de estudios. (Notas tomadas del discurso pronunciado por la profesora jubilada María Teresa Velásquez en la celebración de los 25 años de existencia del programa de Trabajo Social en la Universidad de Caldas).

Prospectiva. Revista de Trabajo Social e intervención social • No. $29 \bullet$ ene.-jun. $2020 \bullet$ pp. 01-38 e-ISSN: 2389-993X • Doi: 10.25100/prts.v0i29.8097

Universidad del Valle - Cali, Colombia 
Esta reflexión se inspira en el contexto de la experiencia acumulada en los diferentes tipos de práctica realizadas, la cual más que una práctica académica con un contenido político, se convirtió en una práctica política sin profundizar en su contenido académico profesional, promovida en sindicatos obreros, organizaciones barriales, organizaciones campesinas, pobladores urbanos, que impulsaban sus luchas por el derecho a poseer una vivienda digna o contar con una red de servicios públicos. Un claro ejemplo, lo constituye en Manizales el llamado movimiento social urbano conocido como "Protecho". Si algo merece ser destacado de este período, fue el compromiso ideológico-político de quienes propiciaban estas ideas por ligarlas a la acción concreta, no eran simples discursos academicistas cómodamente instalados en los recintos universitarios; por el contrario, se trataba de articular la teoría con la acción, realizando un trabajo comprometido con los sectores populares tanto en el ámbito rural como urbano.

El planteamiento general del que se partía sostenía que el Trabajo Social reconceptualizado, para poder responder a las condiciones concretas de la realidad, tenía que ser una práctica social concientizadora, liberadora y emancipatoria. La evaluación de las tensiones y contradicciones generadas en este proceso, hizo posible avanzar en la elaboración inacabada de esta reflexión. Los resultados obtenidos - el análisis de las experiencias vividas - llevaron a considerar que todo este período se caracterizó por una mezcla heterogénea de enfoques teóricos y por una diversidad de posiciones ideológicopolíticas; estas últimas estuvieron incluso casi siempre por encima de una necesaria reflexión teórica-conceptual, que había que realizar desde la perspectiva del quehacer o de la intervención profesional.

A partir de estas experiencias, surgió la necesidad de realizar una reflexión sobre sí la Reconceptualización tal como se estaba conceptuando y practicando, era realmente en ese momento histórico la opción más adecuada para superar el problema del dilema en que se encontraba el Trabajo Social en nuestro medio. Sin embargo, en el desarrollo de esta propuesta se encontró que ese cuestionamiento no podía seguir dándose en abstracto, solamente en el plano de las ideas, partiendo sólo de las posturas ideológico-políticas que hasta ese momento eran conocidas; se imponía la necesidad de reflexionar, evaluando los resultados y los procesos llevados a cabo en el contexto de la realidad concreta, porque sólo a partir de ese análisis tendría plena validez el entrar a ver en qué términos se podría formular la necesidad de promover el replanteamiento de la profesión en Colombia. Sólo a partir de estas cuestiones fundamentales se podría ver sí lo que se enunciaba como salida a la profesión en su lucha por redefinirse en ese momento histórico, no era más que una "bella utopía", que por supuesto compartíamos muchos jóvenes y, algunos profesores con muy buenas intenciones de asumir este compromiso, promoviendo procesos de cambio social y transformación de la sociedad 4 .

${ }^{4}$ Este texto originalmente hizo parte de la tesis de grado presentado por el autor inicialmente como proyecto de grado en la Universidad Nacional y luego en la Universidad de Caldas en el año de 1974, bajo el título: "Dependencia, Universidad y la Reconceptualización del Trabajo Social" (Estrada, 1974) como requisito para obtener el título en Trabajo Social, el cual fue calificado por el jurado evaluador como tesis meritoria. El texto correspondiente al capítulo III del informe ha sido reelaborado y sometido a una revisión crítica, manteniendo, sin embargo, algunas de las ideas generales formuladas en el texto referenciado, cuyo título era: ¿Se puede hablar de 
En un contexto nacional de crisis, de debate en torno al problema del subdesarrollo, de la dependencia de nuestro país frente a los centros hegemónicos de poder mundial, la difusión de las ideas reconceptualizadoras coinciden en Colombia con la existencia de un clima social y político en donde la lucha obrera-campesina tuvo un papel muy importante. En este contexto la lucha estudiantil universitaria de la época se articula jugando un notable activismo, de hecho, algunos de estos liderazgos correspondían a sectores estudiantiles vinculados a los programas de: Trabajo Social, Medicina, Agronomía, Derecho y Filosofía. Este movimiento universitario que se desarrolló en el ámbito local y, nacional, estuvo influenciado por muchas de las propuestas, ideas, proclamas, consignas del "Manifiesto de Córdoba", y también por la rebelión estudiantil de "Mayo del 68" en Francia5.

Es necesario hacer especial énfasis en la necesidad de promover una reflexión que permita examinar, la influencia y la validez que tuvieron estas ideas en las propuestas de formación curricular formuladas durante el proceso de redefiniciones vivido en Colombia y en América Latina. El tema no queda agotado, por el contrario, se espera que estos planteamientos lleven a promover el espíritu analítico y crítico que conduzca no a la polémica estéril sino a la profundización y generación de un conocimiento que posibilite realmente comprender y analizar el impacto y los aportes que tuvo este movimiento en la renovación de la formación académica, también del ejercicio profesional en nuestro país, asunto sobre el cual poco se ha investigado y muy poco se ha escrito en nuestro medio ${ }^{6}$.

En el contexto contemporáneo esta reflexión adquiere un mayor interés, ya que en el ámbito de algunas Universidades Latinoamericanas encargadas de la formación en Trabajo Social, se viene promoviendo un "marxismo academicista" que entre otras cosas empobrece esta concepción como una teoría de la acción política, en la medida en que de hecho se vienen convirtiendo en los pregoneros de viejas doctrinas bajo nuevos mensajes, reviviendo el supuesto que la profesión se tiene que comprometer, asumiendo la transformación macroestructural de la sociedad y la liberación y emancipación de los oprimidos. En Colombia, como en otros países de la Región Andina este proceso se vivió de manera comprometida desde el punto de vista ideológico-político, a diferencia de lo que estaba sucediendo en ese momento en los países del Cono Sur. Intentar revivir el pasado acríticamente sin aprender las lecciones de la experiencia y de la historia, nos conduce a

Reconceptualización en el Trabajo Social? Este texto se constituyó de hecho en el primer intento de reflexión crítica que se escribió sobre esta temática en Colombia.

${ }^{5}$ En los círculos universitarios de la época se estudiaba y se discutía sobre la proclama estudiantil contenida en el "Manifiesto" de Córdoba de 1918, pero también, en las ideas y consignas que se produjeron durante el "Mayo Francés del 68". Estas ideas tuvieron una notable difusión en el movimiento estudiantil colombiano que se produjo entre 1969 y 1971, ejerciendo un importante impacto en sus planteamientos, objetivos y consignas tanto en el ámbito local como nacional.

${ }^{6}$ Se debe señalar el artículo de Liliana Torres (2005) Reflexiones en torno al Movimiento de Reconceptualización. También hay que destacar la publicación que recientemente ha aparecido sobre el tema y sobre este período. Quintero (2018). Contexto, tendencias y actores de la Reconceptualización. Este artículo como lo señala su autor es una versión ampliada y revisada de la ponencia "El movimiento profesional latinoamericano de los años 60-70 y sus posibles impactos en Colombia, presentada en el XIV Congreso colombiano de Trabajo Social realizado en 2013 en Bogotá. Constituye resultados parciales de los estudios de maestría y Doctorado realizados entre 2012 y 2018 en la Universidad Federal de Rio de Janeiro y la Universidad del Estado de Rio de Janeiro.

Prospectiva. Revista de Trabajo Social e intervención social • No. $29 \bullet$ ene.-jun. $2020 \bullet$ pp. 01-38 e-ISSN: 2389-993X • Doi: 10.25100/prts.v0i29.8097 Universidad del Valle - Cali, Colombia 
afirmar, como lo han planteado algunos autores, que el que no conoce la historia está condenado irremediablemente a repetirla, unas veces como comedia y otras veces como tragedia.

\section{El aporte de la "Generación del 65" al replanteamiento profesional}

A la "Generación del 65" le cabe el mérito de haber iniciado un proceso de cuestionamiento, como lo plantea Kruse (1969):

A partir del reconocimiento de "la frustración por los primeros fracasos, una inquietud por el futuro de la profesión compartida con colegas de Argentina, Brasil y Uruguay y una profunda necesidad de dar una respuesta válida a la crisis socioeconómica que afrontaban los países sur-atlánticos, llevaron al sector más inquieto de los profesionales a tentar una nueva conceptualización del servicio social. El propósito era convertir al asistente social en un instrumento del desarrollo, en un agente de cambio, en un concientizador del subdesarrollo, que promoviera a los beneficiarios de sus servicios a ser hombres dispuestos a construir un nuevo Uruguay. El grupo no tenía ni una estructura formal, ni ningún compromiso ideológico dado que lo integraban por igual marxistas, católicos conciliares, desarrollistas de buena fe etc. (p.3).

El contexto que se vivía posibilitó empezar a repensar la formación y el que-hacer profesional, inicialmente en algunos países, dando lugar posteriormente a la configuración de un complejo movimiento en el campo Latinoamericano, el cual hay que entenderlo no como una simple agitación o, circulación de ideas homogéneas, sino más bien como un movimiento heterogéneo configurado por diversas corrientes o tendencias. Este proceso que se inicia en el Cono Sur luego se extendió con mucha fuerza desde La Patagonia hasta el Rio Bravo, aunque lógicamente con desarrollos y resultados desiguales. Las principales ideas se pueden resumir en los siguientes planteamientos:

1. La profesión surgió en Latinoamérica como resultado de un proceso de trasplante mecánico, de una sociedad industrial desarrollada como la norteamericana, a una serie de países subdesarrollados y dependientes.

2. Cuestiona el orden económico capitalista y en particular el capitalismo dependiente y la situación de injusticia social, así como también la pobreza generada por este modelo económico en América Latina.

3. La reflexión crítica sobre la profesión se debe articular a un proceso de cuestionamiento sobre el carácter del subdesarrollo, la dependencia de estos países de los grandes centros metropolitanos de poder mundial.

4. Cuestiona la formación y el quehacer profesional, al señalar la condición de meros instrumentalizadores de técnicas, tratando de adaptar a las víctimas de la sociedad; sin embargo, como se anotaba, los problemas sociales vividos por los individuos no se debían a simples problemas de conducta, desajuste psicológico o desadaptación, sino que correspondían a problemas que tenían su razón de ser en la estructura social.

5. Critica la impotencia de los asistentes sociales o del servicio social en la realidad institucional, para abordar y tratar de solucionar los problemas, las

Prospectiva. Revista de Trabajo Social e intervención social • No. $29 \bullet$ ene.jun. $2020 \bullet$ pp. 01-38 e-ISSN: 2389-993X • Doi: 10.25100/prts.v0i29.8097

Universidad del Valle - Cali, Colombia 
problemáticas sociales existentes en la sociedad, con los métodos y la metodología clásica del Trabajo Social norteamericano.

6. Cuestiona la incapacidad crítica consecuencia de una débil formación académica, que se desarrolla primero bajo una concepción y práctica eminentemente de tipo asistencialista-confesional; cuestiona además, la concepción científica, racional-instrumental promovida por el Trabajo Social norteamericano.

7. Destaca la importancia de estimular el interés por la investigación social de los problemas y problemáticas sociales en el contexto de estos países.

8. Critica la concepción benéfico-asistencialista bajo la cual se formaban los asistentes sociales, así como la formación científica y la racionalidad técnicoinstrumental, que caracterizaba la influencia del Trabajo Social norteamericano en nuestro medio; cuestiona además, la asepsia o neutralidad metodológica y el individualismo metodológico ${ }^{7}$.

9. Inicia este tipo de cuestionamiento con el propósito de convertir al asistente social, en instrumento del desarrollo y en un agente de cambio, es decir, en un concientizador del subdesarrollo, que promoviera a los beneficiarios de sus servicios en procesos de cambio social en estos países.

Desde la perspectiva de la profesión, se puede concluir que la "Generación del 65" cumplió históricamente una función decisiva, ya que - como una de las diferentes tendencias - contribuyó a que se configurara un movimiento, el cual tendría importantes repercusiones en el replanteamiento de la formación y de la práctica profesional. Sin embargo, como lo plantea Kruse (1969), el papel cumplido fue eminentemente el de un cuestionamiento crítico, que se situó inicialmente en un plano ideológico, para luego perfilarse en una perspectiva teórica, donde el tema central giraba en torno a cómo conceptuar lo "social", este es, pensado como una estructura subdesarrollada en la que se vislumbra que esa dinámica del marco social obligaba a pensar la acción profesional en términos de situaciones

${ }^{7}$ En este período no existía una denominación profesional común compartida en el continente en algunos países se denominaba bajo el nombre de Asistencia social, en otros se usaba el término Servicio Social. A partir de la influencia de las ideas de la Reconceptualización se comienza a generalizar el uso de la noción de Trabajo Social que surgió en Norteamérica, aún hoy, no existe una denominación común. Esta situación lo que pone de presente es la necesidad de estudiar la historia del proceso de profesionalización en América Latina; en particular, investigar sobre el origen e institucionalización de la profesionalización académica en cada uno de estos países porque existen marcadas diferencias, que permita superar las miradas lineales y evolucionistas sobre nuestra historia. Sostengo la hipótesis que en América Latina, el origen de la profesionalización académica y la secularización de la formación se inicia como antecedente con la influencia científica y la racionalidad técnico-instrumental del Trabajo Social norteamericano que se promueve a partir de 1950, el cual juega un papel importante en el cuestionamiento del asistencialismo generalizado de corte confesional, que existía en todo el continente. Este proceso de secularización se amplía y se consolida con el movimiento de la Reconceptualización y con la institucionalización gradual de su profesionalización académica en el ámbito universitario. En el caso colombiano la existencia de este movimiento va a coincidir con el comienzo de la inclusión de la profesionalización académica de Trabajo Social, la cual se inicia con la promulgación del Decreto 1297 de 1964, que por Directiva Presidencial estableció la reglamentación de los títulos universitarios y en el que se estipula además, que sólo las Universidades podían expedir títulos profesionales. (Torres et al., 2005, p. 24).

Prospectiva. Revista de Trabajo Social e intervención social • No. $29 \bullet$ ene.-jun. $2020 \bullet$ pp. 01-38 e-ISSN: 2389-993X • Doi: 10.25100/prts.v0i29.8097

Universidad del Valle - Cali, Colombia 
concretas. (Kruse, 1969, p. 2) Sin embargo, hay que subrayar que esta propuesta no logró estructurar en corto plazo una alternativa que desde el punto de vista epistemológico, le permitiera al Trabajo Social en ese momento encontrar un rumbo, una clara orientación en términos de la intervención social profesional.

Por el contrario, el planteamiento más generalizado que se hacía se condensaba en una afirmación que se repetía incesantemente en todos los espacios académicos: "el trabajo social se encuentra en una verdadera encrucijada, por lo tanto se replantea o no tiene razón su existencia". Esta situación evidenciaba la ausencia de un camino claro, se estaba viviendo un agudo dilema. En ese contexto y en un clima de dispersión ideológico-política, fueron también surgiendo los balances críticos, posteriormente aparecieron diferentes replanteamientos teóricos y los nuevos ideólogos - por así decir - del Trabajo Social. Faleiros (1971) distingue para la época dos posturas: entre las distintas tendencias u orientaciones del servicio social hoy en día se pueden distinguir dos: una que se vuelca hacía una cientifización y otra hacía la ideologización del servicio social. Las dos tendencias, para no hablar en corrientes, se fundamentan en posturas distintas respecto de la realidad, como tienen en su haber puntos comunes ${ }^{8}$.

\section{Los orígenes del movimiento de Reconceptualización en Colombia}

Este movimiento se comienza a gestar en Colombia en 1967 a partir del trabajo de pequeños núcleos pioneros existentes en algunas universidades, entre ellas la Universidad Javeriana de Bogotá, Universidad de Caldas, Universidad Nacional de Colombia; sin embargo, rápidamente el liderazgo nacional e internacional lo comienza a asumir con mayor rigor el programa de Trabajo Social de la Universidad de Caldas, con su propuesta metodológica alternativa conocida como el "Método Caldas". Sin duda alguna, la existencia de un movimiento estudiantil en Colombia durante este período contribuyó de manera decisiva para que estas ideas se fueran extendiendo e incorporando gradualmente en los contenidos curriculares de algunos programas de Trabajo Social de otras Universidades, como sucedió con la Escuela de Servicio Social de Cali anexa a la Universidad del Valle desde 1965, Universidad de Antioquia, Industrial de Santander, Cartagena, Externado de Colombia. Al margen y refractarios a estas ideas se mantuvieron inicialmente algunos programas existentes en universidades privadas como: la Universidad Pontificia Bolivariana y la Universidad de la Salle, que tenían fundamentalmente una orientación religiosa confesional.

Sin embargo, a nivel nacional este movimiento al comienzo se va gestando de manera espontánea y un tanto desarticulada, a partir del conocimiento de las principales ideas que se venían agitando, las cuales circularon en los distintos encuentros latinoamericanos y nacionales; otras veces, estas ideas se conocieron a través de las publicaciones impulsadas por el denominado “Grupo ECRO” que luego se convierte en la propuesta Editorial ECRO,

8 Ponencia titulada Ciencia y Servicio Social la cual fue presentada por el autor en el Seminario Latinoamericano de Trabajo Social realizado en Ambato/ Ecuador en 1971.

Prospectiva. Revista de Trabajo Social e intervención social • No. $29 \bullet$ ene.jun. $2020 \bullet$ pp. 01-38 e-ISSN: 2389-993X • Doi: 10.25100/prts.v0i29.8097

Universidad del Valle - Cali, Colombia 
la cual publica en esa época entre otras, la serie Cuadernos del Servicio Social y la revista "Hoy en el Servicio Social" 9.

Este movimiento en Colombia podemos caracterizarlo así:

1. Se origina como consecuencia de un proceso de cuestionamiento iniciado en otros países sobre la filosofía, fines, objetivos y los llamados métodos tradicionales, orientado a cuestionar el tipo de formación académica que se recibía; sin embargo, ese proceso de cuestionamiento en nuestro país es muy limitado desde el punto de vista teórico, teniendo un mayor peso la dimensión ideológica-política, lo que se traduce en ocasiones en que se asumen posiciones emotivas más que posturas conscientes y bien fundamentadas.

2. Se acogen los planteamientos teóricos formulados en el Cono Sur, se empiezan a elaborar nuevos planes curriculares, que van incorporando estas nuevas ideas en los programas académicos, empezando así en cierta medida un proceso de experimentación, de ensayo-error en múltiples direcciones.

3. En el transcurso de estas experiencias se rechaza la realización de las prácticas dentro del marco de las instituciones públicas y de las empresas privadas, más por posiciones ideológicas que por posturas debidamente elaboradas $y$ sustentadas.

4. Este movimiento que se origina y se desarrolla en medio de la confluencia de distintas posiciones ideológico-políticas y diversas posturas teóricas, permite que se le caracterice en nuestro medio como una tendencia bastante heterogénea.

5. Los enunciados teóricos formulados, los enfoques dados en la formación de nuevos profesionales, eran el resultado de esa dispersión y heterogeneidad teórica e ideológico-política; aunque intentaban responder a la realidad social de nuestro país, no se fundamentaron en estudios e investigaciones concretas que tuvieran en cuenta el tipo de formación que se impartía en los Colegios Mayores, las condiciones en que se ejercía la profesión en las instituciones y las características de la realidad social, que permitieran caracterizar los problemas, problemáticas y necesidades sociales más acuciantes de la sociedad. Fue necesario tener que vivir muchos fracasos o errores para empezar a comprender la necesidad de iniciar un ejercicio reflexivo de las experiencias, produciendo así nuevos replanteamientos, lo que en su momento fue un asunto extremadamente complejo, por la falta de flexibilidad sobre todo en las posturas ideológicopolíticas.

6. Las unidades académicas que se fueron incorporando a este movimiento, lograron estructurar propuestas curriculares de programas de estudio, no exentas de contradicciones epistemológicas, teóricas y metodológicas; sin embargo, muchas veces no se contaba tampoco con el grupo humano de docentes, con la requerida formación académica necesaria para el desarrollo de los nuevos planes de estudios y poder así aplicarlos con creatividad e imaginación.

9 Esta publicación posteriormente cambió su nombre por "Hoy en el Trabajo Social", como se le conoce actualmente.

Prospectiva. Revista de Trabajo Social e intervención social • No. $29 \bullet$ ene.jun. $2020 \bullet$ pp. 01-38 e-ISSN: 2389-993X • Doi: 10.25100/prts.v0i29.8097

Universidad del Valle - Cali, Colombia 
La Reconceptualización en Colombia coincide casi que simultáneamente con la institucionalización y profesionalización de la formación académica del Trabajo Social en el ámbito universitario. Esta situación generó agudas controversias, las cuales se comenzaron a plantear en la Universidad Nacional de Colombia, cuando a propósito de la incorporación del programa de estudios de Trabajo Social en la formación universitaria, provocó la crítica por parte de otros profesionales de las Ciencias sociales, los cuales comenzaron a cuestionar en ese momento la pertinencia de la inclusión de la formación en Trabajo Social en la Facultad de Ciencias Humanas.

\subsection{El Programa de Trabajo Social de la Universidad de Caldas como pionero de la Reconceptualización en Colombia}

El papel precursor jugado por la "Generación del 65" dio lugar a la existencia a nivel latinoamericano de una tendencia inicial que rápidamente se tradujo como resultado en un movimiento conocido con el nombre de la Reconceptualización ${ }^{10}$. No es por lo tanto el propósito fundamental en este trabajo entrar a analizar esas tendencias, como tampoco las causas que dieron lugar a su existencia, puesto que otros tienen el mérito de haber señalado, cuál fue su origen, su aporte en el intento de producir una nueva conceptualización de la profesión, de haber avanzado en la formulación de unos enunciados teóricos, pero ante todo de haber promovido una crítica-reflexiva y una postura ideológica.

Sin embargo, hay que señalar que en el desarrollo de la experiencia colombiana no se profundizó lo suficiente en el análisis e implicaciones que tenían estos planteamientos teóricos, ya que incluso algunos eran contrapuestos, en este sentido no se puntualizó sobre la incidencia que tenían estas formulaciones en la formación académica, en el accionar institucional y en el abordaje de la realidad social. De las principales ideas aportadas por los pioneros de la Reconceptualización, se partió para intentar fundamentar la construcción de nuevas alternativas de formación académica. En ese contexto se origina y se construye la propuesta: "Metodología del Trabajo Social para la acción transformadora de la realidad", también conocida como el "Método Caldas" 11.

10 Este movimiento no surge con una estructura homogénea, en su interior confluyeron distintas tendencias o corrientes con diversos enfoques teóricos y distintas posiciones ideológicopolíticas. En este sentido es importante destacar el planteamiento formulado por Kruse (1971) en un artículo titulado "La Reconceptualización en América latina" Selecciones de Servicio Social, N 13, Buenos Aires. En este texto el autor sostiene: "Quien quiera se proponga describir qué es hoy día la Reconceptualización, se equivoca rotundamente -incluso se autoengaña- si cree que es posible conceptuarla y describirla como una unidad homogénea (...) Más aún, los grupos que iniciaron primero ese debate crítico han pasado por períodos en los cuales los temas examinados han ido variando con el decorrer del tiempo." Como plantea De Robertis (2011) "la Reconceptualización fue una búsqueda multidimensional y se enriqueció con enfoques muy diversos, a veces contradictorios, otros convergentes. Kruse la comparaba con una "olla hirviendo". Afortunadamente la Reconceptualización no es un bloque monolítico de ideas y posiciones, sino todo lo contrario, es una "olla hirviente" en la cual bullen tendencias y corrientes no siempre factibles de conciliar entre sí. Es, en síntesis, un movimiento" (De Robertis, 2011, p. 88).

11 "El Método Caldas" se aplicó como fundamentación de la nueva propuesta curricular a partir del segundo semestre de 1969, cuando los profesores establecieron un círculo permanente de estudio, contando como asesores a los hermanos Zabala de la ciudad de Bogotá. Un papel importante

Prospectiva. Revista de Trabajo Social e intervención social • No. $29 \bullet$ ene.jun. 2020 • pp. 01-38 e-ISSN: 2389-993X • Doi: 10.25100/prts.v0i29.8097

Universidad del Valle - Cali, Colombia 
La Enciclopedia plantea que reconceptualizar significa fundamentalmente redefinir, replantear, reactualizar, reformular, reestructurar. Hacerse a una nueva idea; pensamiento o concepto posterior al vigente con el fin de responder a las necesidades epistemológicas, teórico-conceptuales, metodológicas de los tiempos modernos o contemporáneos. Por lo tanto, el replanteamiento de nuestra profesión, no fue y no es el producto de un torpe capricho, sino una necesidad socio-histórica, como consecuencia, por un lado, de la limitada formación profesional que se ofrecía en ese momento; de otro lado, por la incapacidad crítica para abordar el análisis de los problemas, problemáticas sociales y los programas que se ejecutaban en las instituciones de la época en relación con lo social, pero también porque se conceptuaba que la profesión no respondía a las condiciones concretas de la realidad.

Todos estos hechos situaron en primer plano a la profesión y a los profesionales que instalados en una supuesta "neutralidad", persistían en la condición de ser meros instrumentalizadores de unas técnicas; no en vano para aquel momento se les consideraba como auxiliares de otros profesionales, como: médicos, jueces, sociólogos, psicólogos, incluso economistas. Y, surgía un sentimiento de rechazo a esa situación, la razón era clara y en ese momento se reconocía autocríticamente. Ese rechazo no era más que una prueba de incapacidad e impotencia, para participar con solvencia y capacidad profesional analítica, reflexiva y creativa en el desarrollo de los programas, proyectos sociales en igualdad de condiciones con otros profesionales.

Hasta 1964 en Colombia los centros de formación eran Colegios Mayores y Escuelas, sus egresados no tenían mucha conciencia crítica sobre la limitada formación que recibían y que se impartía en estas instituciones denominadas Colegios Mayores², donde se obtenía

lo juega el antropólogo colombiano Manuel Zabala, autor del texto "Metodología sin Método" en el cual se puede advertir una orientación pragmatista, este fue publicado posteriormente por la Editorial ECRO en 1974. La propuesta metodológica fue presentada luego como ponencia en el Seminario Latinoamericano de Trabajo Social, realizado en Ambato-Ecuador en Julio de 1971, siendo designado como ponente por el Departamento de Trabajo Social de la Universidad de Caldas el sociólogo peruano y profesor Henry Felipe Morales.

${ }^{12}$ La formación en Asistencia Social concebida esta como una ocupación se impartía en el caso colombiano en los Colegios Mayores o Escuelas que existían como entidades independientes, por fuera de las Universidades encargadas de la formación profesional en el ámbito Superior. En 1951, las Escuelas de Asistencia Social o de Servicio Social que existían en el país decidieron constituir la Asociación Colombiana de Escuelas de Servicio Social, siendo parte de este grupo fundador los siguientes: Colegio Mayor del Rosario, Colegio Mayor de Cundinamarca, Colegio Mayor de Bolívar, Escuela de Servicio Social de Medellín. Posteriormente se afiliaron la Escuela de Servicio Social de Cali y la Escuela de la Normal Femenina de Santander. Sin embargo, en la década comprendida entre 1965 y 1975 se inicia el traslado de algunos programas de servicio social a las Universidades o se crean otros nuevos usando la denominación de Trabajo Social; este proceso comienza a raíz de la expedición del Decreto 1297 de 1964, el cual establece la reglamentación de títulos universitarios. A partir de ese momento se amplía la formación a cuatro años y se comienza a expedir el título de Licenciatura en Servicio Social, luego este título se modifica por el de Licenciatura en Trabajo Social. Posteriormente en 1984, se amplía la formación a cinco años y se comienza a expedir el título de profesional en Trabajo Social.

Esta Asociación de Escuelas se transformó luego en el Consejo Nacional para la Educación en Trabajo Social el 24 de febrero de 1965, en Asamblea realizada en la Universidad Javeriana de Bogotá. Participaron como miembros fundadores del "CONETS": Colegio Mayor de Cundinamarca, Colegio

Prospectiva. Revista de Trabajo Social e intervención social • No. $29 \bullet$ ene.-jun. $2020 \bullet$ pp. 01-38 e-ISSN: 2389-993X • Doi: 10.25100/prts.v0i29.8097

Universidad del Valle - Cali, Colombia 
Estrada-Ospina

un título intermedio como Asistente Social; sin embargo, se debe destacar que la existencia de este movimiento renovador, en tanto que promueve un proceso de cuestionamiento en relación al origen, al tipo de formación que se impartía, coincide como lo veremos más adelante con la inclusión e institucionalización de la formación académica profesional. En la limitada investigación existente sobre la historia del Trabajo Social en América Latina, poca importancia se le ha dado a la necesidad de diferenciar cual fue su origen como ocupación del momento en que se empieza a fundamentar como una práctica social profesional y también qué papel juega en determinados contextos el proceso institucional de su profesionalización académica y el encuentro con la ciencia. Esta lectura de la historia del Trabajo Social como lo han planteado algunos autores con mucha razón, se ha caracterizado por ser endógena y en una perspectiva evolucionista ${ }^{13}$.

Esta corriente progresista planteaba - a diferencia de la postura conservadora- que era necesario luchar por una formación más amplia, que permitiera avanzar en la fundamentación y comprensión de las principales teorías sociales y políticas, que propiciara contar con mayores elementos para realizar un ejercicio de investigación social sistemática, que posibilitara interpretar críticamente la realidad y la estructura social de nuestro país.

La Reconceptualización en Colombia fue fundamentalmente una tendencia que se planteó inicialmente como tarea cuestionar, es decir, criticar la formación pero sobre todo el tipo de enseñanza impartida. Estos primeros antecedentes se inician en la Universidad Javeriana de Bogotá, donde se comenzó a exigir la introducción de las ideas reconceptualizadas en los contenidos del currículo a partir del año de 1968 ${ }^{14}$. Luego, estos

Mayor de Bolívar, Escuela de Servicio Social de Cali, Universidad Pontificia Bolivariana, Universidad Nacional, Universidad Javeriana.

${ }^{13}$ Es de importancia resaltar y tomar en cuenta las diferencias existentes entre el proceso de configuración de las profesiones como prácticas sociales existentes en la sociedad y los procesos de institucionalización y profesionalización académica en el ámbito universitario y al mismo tiempo también diferenciar que es una ocupación de una profesión. En este sentido Uricoechea (1999) sostiene, "desde una perspectiva histórica el desarrollo de las profesiones ha estado asociado a la interacción que actividades funcionalmente específicas, técnicamente especializadas, establecen con tres principios organizacionales básicos de la estructura social moderna: el Estado (como factor de acreditamiento monopólico), el mercado (como mecanismo de oferta, demanda y adjudicación de puestos) y la división del trabajo (como instrumento de definición de las exigencias técnicas). Además, de estas tres fuerzas, la profesionalización académica requiere de una cuarta condición: la existencia previa de una disciplina o saber académico que permita la constitución de una oferta académica profesional de cargos con relativa estabilidad ocupacional y una (idealmente) exclusiva dedicación.

A su vez, la profesionalización académica de las disciplinas va asociada al desplazamiento de una identidad que se construye menos en términos de la función profesional que en términos de una función disciplinaria. Dicho de otra forma, el estatus dentro de la comunidad ocupacional acaba estando más dado por la posición dentro de la jerarquía académica que por la posición en el mercado profesional extra-académico. El proceso de profesionalización de la docencia en Colombia, que comienza virtualmente durante el segundo cuarto de este siglo, está en parte asociado al proceso de expansión del sistema de educación superior que se inicia, con vigor, desde comienzos de la década de 1970" (Uricoechea, 1999, pp. 4-5).

${ }^{14}$ Estas ideas que se estaban promoviendo en el Cono Sur tienen sus primeros antecedentes en el ámbito colombiano en la Universidad Javeriana de Bogotá, en los programas de Trabajo Social y

Prospectiva. Revista de Trabajo Social e intervención social • No. $29 \bullet$ ene.-jun. $2020 \bullet$ pp. 01-38 e-ISSN: 2389-993X • Doi: 10.25100/prts.v0i29.8097

Universidad del Valle - Cali, Colombia 
planteamientos formulados por la "Generación del 65" los asume en Colombia el programa de Trabajo Social de la Universidad de Caldas, el cual indudablemente comenzó a jugar un papel importante como pionero en la difusión, promoción y defensa de estas ideas a nivel nacional y latinoamericano ${ }^{15}$.

\subsection{El “Método Caldas” y la Reconceptualización}

El "Método Caldas" es una propuesta epistemológica, metodológica que intentó articular aplicando un método de conocimiento con un método de intervención en la realidad en el programa de Trabajo Social de la Universidad de Caldas, enfatizando contribuir en darle a la formación profesional un nuevo giro, epistemológico, teóricoconceptual, metodológico, que tuviera incidencia específicamente en una nueva práctica profesional, como condición para lograr una salida al dilema o a la encrucijada en que se encontraba el Trabajo Social en Colombia. sostenía:

En esta perspectiva Morales (1971) en representación del equipo de profesores

La elaboración de planes de estudio de Trabajo social, como en muchas otras carreras, se han hecho teniendo en cuenta los modelos implementados en otros países. En muchos casos, se han efectuado esfuerzos para adecuarlos a la realidad de cada país, sin conseguir resultados óptimos. De allí que conocedores de tales dificultades nos planteamos en

Sociología (creados en 1961). En ese momento un grupo de profesores y estudiantes que hacían parte del llamado "Movimiento de Cataluña" realizaron una serie de protestas universitarias en 1968, exigiendo entre otras cosas, la introducción de las ideas de la Reconceptualización en los contenidos programáticos del plan de estudios. A raíz de estas protestas los programas fueron clausurados definitivamente en 1971 (Torres, 1988, p. 179). En esta época jugó también un papel muy importante un movimiento cristiano renovador, que luego se transformó en el llamado "Grupo Golconda" (Teología de la Liberación), integrado por algunos sacerdotes jesuitas y por miembros de otras comunidades religiosas considerados como progresistas, estos tenían vinculación con algunos centros universitarios y del cual hizo parte también el destacado sacerdote Camilo Torres Restrepo.

${ }^{15}$ La primera promoción de estudiantes es admitida en 1969, siendo su primer Director Académico el profesor Juan de la Cruz Mojica, Licenciado en Trabajo Social, egresado de la Universidad Javeriana de Bogotá, el cual juega un liderazgo que lo convierte en el más importante promotor y defensor de las ideas planteadas por este movimiento. En una situación de debate y cuestionamiento promovidos a través de los medios de comunicación locales por la orientación académica del programa, es presionado por la dirección de la Universidad a renunciar en 1971. Sale entonces del país vinculándose como docente en una Universidad Chilena. Luego, es nombrado como Director del Centro Latinoamericano de Trabajo Social "CELATS", organismo adscrito en aquella época a "ALAESS" con sede en Lima, Perú, el cual dirige por algunos años; posteriormente, se retira después de mantener una aguda confrontación con algunos miembros del "Grupo ECRO", entre ellos Juan B. Barreix, quien fue uno de sus principales críticos; finalmente, regresa a Colombia y se desvincula por completo de la vida académica pero también del ejercicio de la profesión, rompiendo todos los vínculos profesionales.

El día que se profundice en la historia sistemática de esta experiencia en Colombia, se tendrá que hacer un justo reconocimiento a Juan de la Cruz Mojica, María Teresa Velásquez, Gilma Méndez, Henry Felipe Morales, Julia Reina y Blanca Libia Mejía, destacados miembros del equipo de profesores de aquella época, por el papel y los aportes hechos en ese momento histórico.

Prospectiva. Revista de Trabajo Social e intervención social • No. $29 \bullet$ ene.-jun. $2020 \bullet$ pp. 01-38 e-ISSN: 2389-993X • Doi: 10.25100/prts.v0i29.8097

Universidad del Valle - Cali, Colombia 
actitud de crítica y reflexión, investigando no solo para designar el nombre de las asignaturas del plan, sino para determinar el contenido de cada una de ellas (...) Consideramos absurda la elaboración de un plan de estudios sin tener en cuenta la realidad social existente, porque creemos que el conocimiento de la realidad debe ser el que da los elementos para proveer lo que se carece (...) Toda la riqueza del conocimiento y la metodología científica nos ha permitido, elaborar este plan de estudios, procurando no caer en esquematismos. En última instancia, el hombre como ser social, demostrado científicamente, es consciente, reflexivo, profundamente crítico y extraordinariamente creativo, y nuestro objetivo en razón de este conocimiento, no es sino, devolverle al hombre esa posibilidad de desarrollar estas cualidades, que por motivos de conveniencias históricas le han sido negadas. (p.19).

La intencionalidad era sin lugar a dudas renovadora, a pesar de la existencia de algunas inconsistencias teóricas y tensiones conflictivas implícitas en la estructura de la propuesta curricular, por ejemplo en los fundamentos científicos, se critica a las Ciencias Sociales en América Latina por haber caído en la "indiferencia moral", por quedarse únicamente en "el conocimiento contemplativo de la realidad" y por no atreverse a actuar transformadoramente. Sin embargo, en la misma propuesta Morales (1971) plantea:

La ciencia social puede y debe integrarse formando una unidad que estudie, plantee y transforme la estructura social enfocándola globalmente (...) Así mismo el trabajador social, puede y debe hacer una integración de los conocimientos científicos provistos por las disciplinas de la ciencia social, tales como: ecología, economía, sicología, antropología, derecho y sociología en su práctica social profesional. (p. 9).

Esta es una tensión que no se pudo resolver de manera creativa e imaginativa en el proceso de formación y en el desarrollo de las distintas experiencias. Sin embargo, a partir de estas afirmaciones contradictorias en sí mismas, fue posible formular algunos interrogantes y profundizar en el análisis. Si se critica a las demás Ciencias Sociales, por su indiferencia moral, por ser esencialmente contemplativas $\mathrm{y}$, además, por ser positivistas y estructural-funcionalistas ¿cómo se podrían retomar el aporte de estas ciencias como la base para la fundamentación en la formación y en la acción social profesional de los trabajadores sociales dentro de una visión reconceptualizada? Si las Ciencias Sociales se caracterizaban por ser positivistas-funcionalistas ¿Qué es lo que puede integrar el Trabajo social en su práctica transformadora de la realidad? Por supuesto, existían más preguntas que adecuadas respuestas a las evidencias teóricas contradictorias existentes en ese momento histórico. ¿Cómo entonces conceptuar el cambio social y la transformación social? Sin embargo, hay que reconocer que al incorporar el conocimiento de las diferentes teorías sociales y políticas mejoró notablemente el proceso cualitativo formativo en Trabajo Social.

Esta propuesta indudablemente sirvió de punto de partida para comenzar a gestar una nueva experiencia de formación, bajo rigurosas exigencias y en un clima intelectual, político y cultural de mucha discusión y debate, rompiendo de entrada con propuestas curriculares pensadas para otros contextos e inspiradas en una formación clásica o tradicional. Sin embargo, como toda experiencia renovadora no estuvo exenta de desafíos y errores, la experiencia demuestra que cuándo se inicia un proceso de construcción de cambios hay que asumir las consecuencias que se producen en dichos procesos, ya que no existe otro camino posible.

Prospectiva. Revista de Trabajo Social e intervención social • No. $29 \bullet$ ene.-jun. $2020 \bullet$ pp. 01-38 e-ISSN: 2389-993X • Doi: 10.25100/prts.v0i29.8097 Universidad del Valle - Cali, Colombia 
A partir del segundo semestre de 1969 en el programa académico de Trabajo Social de la Universidad de Caldas, se constituyó un grupo de estudios del cual hacían parte el equipo de profesores y algunos estudiantes destacados de la época ${ }^{16}$, donde continuó la reflexióndiscusión que concluyó en la formulación de una nueva propuesta metodológica. En la introducción de esta alternativa metodológica se hacían básicamente dos importantes formulaciones, que se deben resaltar por su importancia y trascendencia. En primer lugar, se insistía en la necesidad de tomar como referencia el proceso de reflexión crítica que para la época venía ya adelantando el Trabajo Social norteamericano. Este planteamiento, toma distancia con la afirmación que se había venido sosteniendo por parte de algunos sectores, que el Trabajo Social latinoamericano era el resultado de una copia mecánica del Trabajo Social norteamericano, el cual desde su origen estaba centrado en la adaptación de los desadaptados a la estructura social17. Sin embargo, es necesario precisar que en ese momento muy pocos tenían claridad a nivel continental sobre los cambios y transformaciones experimentadas en el Trabajo Social norteamericano, entre ellos se destaca Kruse (1969) quien para la época señalaba:

El Trabajo Social en EE.UU. ya había abandonado la influencia reformadora de las pioneras al estilo de Mary Richmond; que había superado el impacto psicologizante de la Pensylavania School y se estaba reponiendo del impacto que produjo la crisis de 1929. (p. 2).

${ }^{16} \mathrm{El}$ grupo de profesores de aquella época estuvo integrado por los siguientes trabajadores sociales vinculados en diversos momentos: Juan de la Cruz Mojica (primer director de la Carrera), María Teresa Velásquez, Nelly Alfonso (q.e.p.d.), Marco Carvajalino, Julia Reyna, Gilma Méndez, Antonio Valencia, Luz Helena Velásquez y Luis Ernesto Rodríguez; sociólogos: Blanca Libia Mejía, Henry Felipe Morales y la antropóloga María Mercedes Gutiérrez. El grupo de estudiantes más activo estuvo integrado por: Euclides Arboleda, Guillermo Navarro, Alberto Sánchez, Mario Gonzáles, María Helena Rincón, Martha Inés Morales, Luz Estela Martínez y Víctor Mario Estrada; luego se vincularon: Hernán Cortés y Lucia Jaramillo, estudiantes procedentes de la Universidad Javeriana de Bogotá. Algunos de ellos jugarán un liderazgo importante a nivel local en las luchas universitarias de la época, en el período comprendido entre 1970 y 1972; unos serían sancionados, otros expulsados por su activismo y liderazgo en la Universidad de Caldas.

${ }^{17}$ Hay que señalar que este movimiento reconceptualizador en América Latina, coincide con el proceso de reflexión crítica que se había iniciado por parte del Trabajo Social norteamericano a partir de 1965 en torno a la integración de métodos. En ese sentido Vásquez, 1971 citado en Lima (1975) sostiene que, "el marco referencial de esta nueva postura metodológica parte de tres enfoques diferenciados: El enfoque I, que gira en torno al método comprensivo de intervención: es la búsqueda de un método común de intervención para solucionar los problemas sociales. Un enfoque II, que se manifiesta por la imposibilidad de la total integración entre los tres métodos tradicionales, debido a sus características diferenciadoras. Un enfoque III, que propugna la elaboración de una metodología flexible, que diluya las rígidas líneas existentes entre los tres métodos básicos. Una variante del grupo I, pero que debido a elementos cualitativamente diferenciados surge como otro enfoque particular es el Método Básico o Método Único desarrollado posteriormente en Suramérica. Otro enfoque también sudamericano señala Lima (1975), es el que se encamina no ya a encontrar la integración o lo común a los métodos clásicos del Trabajo Social, sino a buscar otros modelos de acción profesional (Modelo de Intervención en la Realidad, Universidad Central de Venezuela).

Vásquez, 1971 citado en Lima (1975) referencia que el grupo I estaba representado por: William Gordon, Mark Hale y Khaterin Papel. El Enfoque II defendido por: Katherine Kendal, Eveline Burns, EileenYounghusband y Enmanuel Tropp. El grupo III a favor de una metodología flexible, por: Kaduchins Alfred, Walter Kindelsperger, Winnifred Alfred" (pp. 120-121).

Prospectiva. Revista de Trabajo Social e intervención social • No. $29 \bullet$ ene.-jun. $2020 \bullet$ pp. 01-38 e-ISSN: 2389-993X • Doi: 10.25100/prts.v0i29.8097 Universidad del Valle - Cali, Colombia 
Estrada-Ospina

Este movimiento de Reconceptualización dada su naturaleza heterogénea, en algunos países distorsionó en parte esta realidad, por desconocimiento o por razones ideológicopolíticas, ya que se enfatizaba una idea equivocada sobre el origen y fundamentación del trabajo social norteamericano. Aún hoy se continúa planteando por parte de algunos sectores esta postura, cuando erróneamente siguen insistiendo que esta profesión tuvo su origen adaptando los llamados "desadaptados" o "desviados sociales" a la estructura social.

A esta idea completamente distorsionada sobre el origen de la profesión, se sumaba el total desconocimiento de los fundamentos fundacionales del Trabajo Social como profesión y la negación e invisibilización de las obras de las principales pioneras o clásicas. Este desconocimiento como también la negación sistemática de sus fundamentos filosóficos, teórico-conceptuales y éticos tendría repercusiones negativas en la formación de las nuevas generaciones, pero sobre todo, profundas consecuencias adversas tanto en su fundamentación como en la construcción de la identidad profesional. Al negar y distorsionar el origen de la profesión, al subestimar la necesidad de conocer y estudiar sus destacadas pioneras o clásicas, nos quedamos sin historia, sin memoria y por supuesto sin referentes de identidad sobre el origen y sus antecedentes fundacionales. Sin embargo, es necesario tener en cuenta desde el punto de vista socio-político que en Latinoamérica lo que se produjo fueron parciales revoluciones políticas de independencias, acá no ocurrieron grandes revoluciones políticas e ideológicas y tampoco sucedieron revoluciones industriales que transformaran de manera total la estructura de las sociedades; el origen de esta profesión se convirtió en mito y éste a su vez en enigma. ¿Cómo entonces explicar su origen, si ella precisamente no había surgido en el contexto de América Latina? ¿Cómo ir fundamentando y construyendo una profesión-disciplina en un contexto por cierto completamente diferente, sin ningún tipo de relación de identidad y sin referenciar tampoco el contexto socio-histórico en que este proyecto como profesión-disciplina se hizo posible?

En esta línea de pensamiento Travi (2010) afirma:

Nos preguntamos entonces ¿cómo puede subsistir una profesión/disciplina que re-niega de sus orígenes y que considera que todo lo que "viene de afuera" es mejor, más crítico, más comprometido? ¿Cómo podremos construir un sólido aparato teórico-conceptual sobre los temas de nuestra incumbencia y especificidad si no reconocemos ni valoramos nuestro acervo de conocimientos y experiencias acumulados y vivimos pendientes de las "modas" para correr a comprar" las últimas novedades que producen otras disciplinas, sin ni quiera desentrañar sus orígenes?

Insistimos una vez más en la importancia de la investigación teórico-disciplinar como alternativa para contrarestar cierta forma de "epistemicidio disciplinar", para lo cual es impostergable la "vuelta a las fuentes", el rastreo y el análisis crítico de los principales conceptos/categorías que fundamentaron ayer y hoy el esquema conceptual del Trabajo Social.

Tenemos la convicción que de esta manera contribuiremos a fortalecer nuestra identidad profesional, a establecer un "diálogo" en igualdad de condiciones con las "otras disciplinas" y aportar a la comprensión de la complejidad social, al mejoramiento de la sociedad y al cumplimiento de los objetivos emancipadores que dieron origen a nuestra profesión. (pp. 39-41).

Prospectiva. Revista de Trabajo Social e intervención social • No. $29 \bullet$ ene.-jun. 2020 • pp. 01-38 e-ISSN: 2389-993X • Doi: 10.25100/prts.v0i29.8097

Universidad del Valle - Cali, Colombia 
Como se ha destacado lo que primó durante mucho tiempo fue el desconocimiento de los referentes de su fundamentación profesional-disciplinar, pero también, se ignoró el contexto socio-histórico en que este proyecto se construyó y fue posible en Norteamérica y el papel fundamental que juega desde la práctica profesional el encuentro con la ciencia y la institucionalización de la formación académica en las mejores universidades. En este sentido en Latinoamérica como en España ocurrió la misma situación, tal como lo plantea Miranda (2003):

De la etiqueta asistencialista quedaron a salvo en general, algunos autores latinoamericanos empeñados en reconceptualizar la disciplina desde su propia realidad aún a costa, en algunos casos de enturbiar y de acudir a clasificaciones fáciles, pero erróneas, para entender lo que sucedía al norte del Rio Grande, inventando así su propia historia y la de los demás. Lo que parece claro es que bajo la etiqueta del asistencialismo y funcionalismo se rechazó no sólo en Latinoamérica toda la tradición anglosajona.

En el contexto de explotación económica, opresión política y dominación ideológica que durante décadas practicó el vecino del Norte este rechazo parece comprensible. El marxismo proporcionaba elementos de análisis y orientaba la intervención con mayor eficacia que ningún otro paradigma inclinando la balanza hacía lo comunitario. En consecuencia, en el terreno de trabajo social, todo lo que sonara a intervención individual se descartaba por inapropiado y políticamente incorrecto. Se rechaza el psicologismo del Trabajo Social norteamericano pero no el Psicoanálisis, lo que parece paradójico teniendo en cuenta que fue precisamente el "diluvio psiquiátrico" y el Psicoanálisis como parte fundamental de ese diluvio, lo que influyó de manera determinante en el Trabajo Social (y en las demás Ciencias Sociales). Se estigmatiza la intervención individualizada y de paso, seguramente por desconocimiento, se echa al cubo de la basura lo mejor de la tradición anglosajona, desde el principio, vía Jane Addams y el movimiento de los settlements houses, (casas dónde el propósito era poner en contacto personas con dificultades sociales, para que se implicaran en los problemas sociales del entorno) pero también en M. Richmond y en la C.O.S (Charity organisation society); el debate teórico y la práctica de otros niveles de intervención grupo y comunidad. Se reclama la necesidad de tener en cuenta la influencia de la ideología, pero no se hace un detenido examen de la ideología subyacente en los modelos que se critican porque la aplicación de la etiqueta evita el esfuerzo de tener que entrar en ese tipo de análisis. (pp. 11-12).

Al contrario de lo que venía sucediendo en este período Morales (1971) a nombre de los profesores del Departamento de Trabajo Social de la Universidad de Caldas presentaba otra mirada muy distinta de lo que venía sucediendo con el Trabajo Social norteamericano:

Largo y ampliamente debatido se encuentra el Trabajo Social como teoría y como método (...) tan cierto es esto, que actualmente, los trabajadores sociales del país en el que alcanzó el más alto nivel de desarrollo, lo están cuestionando y hasta ven la necesidad de descubrir nuevas formas de acción que respondan, justamente, a esa nueva realidad en donde se pretende aplicarlas. ¿Acaso el "método único" o "método integrado" o "método genérico" del que tanto se viene hablando en los Estados Unidos, no es una respuesta concreta a esa preocupación por descubrir nuevas formas de acción dentro del Trabajo Social norteamericano? Si esto es cierto, ¿Por qué nosotros en América Latina, pretendemos insistir y sostener aún, lo que es caduco hasta para el país que lo creó? (p. $3)$. 
Este planteamiento para la época era absolutamente sorprendente, puesto que la afirmación que se repetía en todos los textos que promovían las ideas renovadoras de la profesión, enfatizaban en que el Trabajo Social norteamericano había surgido adaptando a los disfuncionales y desviados sociales a la estructura social. Muchos no distinguían el origen progresista, reformista que tuvo en el comienzo la profesión, de la concepción positivista, estructural-funcionalista que se hizo hegemónica en el ámbito de las Ciencias Sociales y en particular en el trabajo social norteamericano a partir de 1930, influencia que se extendería posteriormente por toda América Latina en la década del 50.

Aunque los antecedentes fundacionales del Trabajo Social se producen como lo plantea Miranda (2003) en el contexto de Inglaterra, el proyecto se cristaliza y se fundamenta en los Estados Unidos, primero como profesión y rápidamente se constituye como disciplina, con una orientación y vocación aplicada, fundamentándose filosóficamente en el pragmatismo y teórico-metodológicamente en el interaccionismo simbólico. Sin embargo, cuando se comienza a experimentar la influencia del Trabajo Social norteamericano con una ya marcada orientación positivista-funcionalista en nuestro medio a partir de 1950, ya se había transformado conservadoramente en una profesión centrada en la adaptación de los denominados desadaptados o desviados sociales. Efectivamente, terminada la II Guerra Mundial esta fue la influencia que nos llegó a América Latina, pero ya se habían abandonado en alguna medida gran parte de sus fundamentos filosóficos, teórico-conceptuales, metodológicos iniciales, que habían sido enunciados por las pioneras o clásicas, que enfatizaban en la importancia de la investigación diagnóstica, como la base de la intervención social profesional y cuyos elementos sirvieron de fundamentación en los comienzos de su constitución profesional-disciplinar.

Sin embargo, sostengo la siguiente hipótesis de trabajo: en contracorriente de lo que muchos piensan, el Trabajo Social norteamericano al enfatizar una formación científica y una racionalidad técnico-instrumental y al fundamentar la formación en sociología y psicología, entraría a jugar un papel positivo en el contexto de América Latina, por cuanto contribuyó a fundamentar la formación y a poner en entredicho la práctica de un asistencialismo de corte confesional, con una orientación paramédica y parajurídica; esta perspectiva coadyuvó a la iniciación de un proceso de secularización de la formación que se fundamentaba en una moral y una ética religiosa y esta tendencia se profundizó radicalmente con la existencia y desarrollo del movimiento de la Reconceptualización.

Al crearse las primeras escuelas de asistencia social en el Cono Sur como lo plantea Miranda (2003) se empezó a sentir la influencia que nos llegó a comienzos del siglo XX como expresión más atrasada del "catolicismo social” Belga, y del “Nacional-catolicismo" español que promovía la UCISS, (Unión Católica Internacional de Servicio Social), la cual fue fundada en 1925 en Milán Italia por María Baers, organismo dependiente que actuaba bajo los lineamientos de la Unión Católica Internacional (UCI) que había sido creada en Bélgica en 1921, la cual empezó a promover estas ideas y prácticas de asistencia social incorporando algunos elementos de tipo técnico, pero bajo una fuerte influencia confesional católica 
pasada la I Guerra Mundial, con el propósito de neutralizar, y combatir las ideas liberales y socialistas ${ }^{18}$.

A comienzos del primer cuarto del siglo XX en el contexto de América Latina, surgen las primeras escuelas de asistencia social concebida como una ocupación, fundamentándose en una concepción benéfico-asistencialista que se mantuvo hasta la II Guerra Mundial. En este contexto particular Kruse (1969) afirmaba:

Comenzaron a funcionar a nivel continental algunos programas de alcance social, como por ejemplo, el Servicio Cooperativo Interamericano de salud pública. En estos programas concebidos por expertos norteamericanos, el asistente social tenía su lugar propio en el equipo de técnicos y donde no los había capacitados para esta nueva función, un generoso sistema de becas los capacito en los EE.UU. Recibimos así el impacto metodológico del (Trabajo Social) norteamericano (...) Nosotros nos deslumbramos con la metodología, con el decantamiento de una experiencia científicamente controlada, con la profunda formación sociológica y psicológica en contraste con nuestra formación paramédica y parajurídica, con el status del asistente social en el equipo de profesionales. Y nos pusimos a copiar expertos de Naciones Unidas, mediante los programas de las escuelas norteamericanas. (p. 2).

En estas condiciones, se puede plantear que esta primera influencia del Trabajo Social norteamericano incentivó una formación inspirada en una racionalidad técnicoinstrumental, con una clara orientación estructural-funcionalista, con la cual se insistía en la necesidad de una sólida formación científica, esta se fue configurando de manera progresiva en todo el continente. Sin embargo, Kruse (1969) afirmaba:

A nadie se le ocurrió que ese Servicio Social que era una técnica trasplantada para dar frutos exigía ciertos requisitos que no se habían dado en el Uruguay. Nosotros no teníamos agencias. Nuestras instituciones sociales eran, o el remanente anquilosado de esfuerzos de la caridad y la filantropía o los frutos dispersos de una sucesión de concepciones doctrinarias distintas del Estado, esterilizados por la burocracia, la falta de miras, la inadecuación de los recursos asignados y la corrupción política y administrativa. Cuando los asistentes sociales llegaron a esas instituciones y quisieron aplicar su

18 "La primera Escuela de Asistencia Social en Colombia se fundó en 1936, anexa al Colegio Mayor de Nuestra Señora del Rosario que tenía una orientación católica confesional, promovida por María Carulla Soler de origen catalán egresada de la primera promoción de la Escuela de Asistencia Social de Barcelona que había sido creada en 1932 bajo influencia católica Belga; esta escuela en Colombia comenzó a funcionar en 1937 y fue reconocida por el Gobierno Nacional, según resolución N³17 de 1940, fue cerrada veinte años después, pero graduó durante este período a 95 asistentes sociales (Malagón, 2012, p. 280). Todas las Escuelas de Asistencia Social o de Servicio Social que se crearon en el continente se fundaron siguiendo la orientación de la Unión Católica Internacional de Servicio Social (UCISS). En América Latina las primeras escuelas de asistencia social se crearon en Chile: Escuela Alejandro del Rio (1925) y la Escuela Elvira Matte de Cruchaga (1929). “El pensum planeado para la preparación de los asistentes sociales seguía los lineamientos de la UCISS. Entre sus fines se proponía: impulsar la formación a la luz de los principios católicos, científicos y prácticos del servicio social; desarrollar el servicio social para contribuir a la construcción de un orden social en el mundo moderno; promover la creación de escuelas de servicio social y de grupos católicos de acción social; representar en el terreno internacional oficial o privado el punto de vista católico en lo que concierne al servicio social" (Martínez, 1981, p. 39).

Prospectiva. Revista de Trabajo Social e intervención social • No. $29 \bullet$ ene.-jun. $2020 \bullet$ pp. 01-38 e-ISSN: 2389-993X • Doi: 10.25100/prts.v0i29.8097

Universidad del Valle - Cali, Colombia 
esquema teórico de "investigación-diagnóstico-tratamiento" para hacer trabajo de caso, o más aún cuando intentaron aplicar esas "cosas raras" que eran hace 10 años los métodos de grupo y comunidad, para los que estaban dentro de las instituciones fue como si hubieran llegado los marcianos. Realmente, los asistentes sociales parecían seres de otro planeta. El resultado de esa inadecuación entre la formación del profesional y el marco institucional dentro del que debían actuar fue el choque, la pugna, la depresión y, para muchos la frustración. Era difícil comprender qué sucedía, por qué esos métodos nuevos, científicos, universalmente aceptados no tenían anclamiento en nuestros organismos públicos. A veces se chocaba con un reglamento, en otras, con un jefe, siempre, contra una estructura institucional. (p. 2).

Esta tensión contradictoria entre formación técnico-instrumental y realidad institucional, es lo que va a estimular en gran medida estos primeros intentos de conceptualizar un nuevo fundamento profesional, lo que va a permitir la búsqueda de un marco de referencia crítico que de manera sistemática tome en cuenta las características y condiciones de nuestras realidades sociales; es también el punto de partida de búsquedas teóricas con el fin de precisar marcos de referencia, que le permita al trabajo social como profesión encontrar un papel real en el ámbito de intervención profesional, teniendo como referente el contexto y la expectativa cada vez creciente de aportar a los procesos de cambio y transformación social.

En el caso de Colombia este proceso de cuestionamiento evidenció la limitada capacidad para intervenir profesionalmente, pero también las carencias epistemológicas, teórico-conceptuales, metodológicas, y en particular la ausencia de una actitud y de un pensamiento crítico; limitaciones que por el tipo de formación que se imparte impide realizar el análisis de los problemas y problemáticas sociales concretas (incluso de los mismos programas sociales que se desarrollan y en los cuales se participaba). La ausencia de una rigurosa formación en el conocimiento de las teorías sociales y políticas, así como también las limitaciones formativas en investigación social pesaban notablemente en sus prácticas; era evidente que la falta de ese espíritu o disciplina investigativa, limitó y condicionó al llamado servicio social de la época, colocándolo como el agente neutral que orientado por la "asepsia metodológica" y el "individualismo metodológico" reproduce acríticamente la ideología dominante en su función adaptadora del hombre al orden social.

El análisis crítico de esta realidad permitió responder categóricamente que el replanteamiento profesional era una necesidad no solamente teórica sino también práctica. Aunque el problema inicial ha sido en parte superado, este período no ha sido adecuadamente estudiado y evaluado en Colombia, de manera que permita comprender este complejo proceso de Reconceptualización con sus graves errores, pero también con sus extraordinarios aciertos. El problema hoy es cómo continuar promoviendo este proceso de reflexión y hacía dónde orientarlo definiendo unos claros y posibles fines y objetivos de la profesión en el contexto de la hoy denominada posreconceptualización ${ }^{19}$.

19 En Lima Perú entre los días 31 de octubre y el 7 de noviembre de 1982, el Centro Latinoamericano de Trabajo Social "Celats", realizó un seminario bajo el título "El Trabajo Social en América Latina: Balance y perspectivas", el cual convocó a un grupo de destacados profesionales de la región. En este evento se hizo un balance de la Reconceptualización tomando como base tres ejes de reflexión que dieron unidad al conjunto de las ponencias y debates realizados así: 1 . La elaboración

Prospectiva. Revista de Trabajo Social e intervención social • No. $29 \bullet$ ene.jun. $2020 \bullet$ pp. 01-38 e-ISSN: 2389-993X • Doi: 10.25100/prts.v0i29.8097 Universidad del Valle - Cali, Colombia 
El segundo planteamiento de enorme trascendencia renovadora para el Trabajo Social en Colombia y en América Latina sostenía según Morales (1971):

No se puede pretender que una metodología del responda a un criterio universal. Debe ser ante todo una necesaria respuesta a una realidad social particular y concreta, puesto que tiene que ver con hombres en relaciones. Relaciones que son respuesta concreta a una realidad espacio temporal, es decir al hombre en relación con otros hombres en razón de un tiempo y un mundo determinados. ¿Por qué insistir en uniformar a los hombres que habitan diferentes partes del mundo? ¿Acaso un habitante norteamericano, con alto nivel de vida, con empleo e ingresos asegurados, es igual a un analfabeta, desocupado, enfermo, y lo que es peor famélico Latinoamericano? (...) Cómo adaptar el hombre a una sociedad en donde la estructura de la familia se desintegra, la estructura política es caduca y se quiebra, la estructura económica genera y conserva la explotación del hombre por el hombre, la estructura religiosa sigue siendo alienante y entre otras, la estructura educativa no da la posibilidad de una formación adecuada para desenvolverse en una realidad social como la nuestra. Si la estructura de la sociedad en que vivimos, es caduca y rígida, es tradicional y arcaica, ¿cómo adaptar al hombre a un orden social inoperante? He aquí el gran dilema de la ciencia actual, la gran encrucijada del Trabajo Social latinoamericano. (pp. 3-4).

Sus autores, aunque realizan una reflexión sistemática sobre los métodos clásicos de intervención profesional, entienden ya la importantísima idea que la profesión no puede continuar reivindicando para sí la existencia de una única metodología clásica universal de intervención profesional, porque no se está frente una realidad social, sino frente a múltiples realidades sociales, con diferencias y particularidades concretas, las cuales tienen mucha importancia en cada contexto particular. Son en nuestro medio también los primeros en asumir implícitamente la necesidad de defender y practicar un pluralismo metodológico, el cual fue difícil de comprender en general en el ámbito Latinoamericano, pero van a ser también los pioneros al establecer una clara diferenciación epistemológica entre método y metodología, como lo reconocerán incluso posteriormente algunos de los más enconados críticos del llamado "Método Caldas". Sin embargo, son también los primeros en Colombia que van a cuestionar la asepsia y el individualismo metodológico, justificando sobre la base

teórica del Trabajo Social; 2. La formación profesional del Trabajo Social; 3. Los determinantes de la práctica profesional del trabajador social. Es precisamente, en el marco de este seminario promovido por el Celats y Alaess, al tiempo que se planteaba abiertamente el comienzo de la posreconceptualización se reafirmaba la necesidad de promover en el continente un Trabajo Social crítico. En este sentido se enfatizaba la necesidad de profundizar "la crítica teórica de las elaboraciones del Trabajo Social que se hacen en el interior del pensamiento modernizador (la corriente "restauradora" o "conservadora") (Celats, 1983, p. 32). No se estaba inventando nada nuevo, de hecho, lo que se estaba privilegiando era la profundización de esta corriente, que había surgido en el proceso de Reconceptualización en el ámbito continental, ahora bajo nuevas perspectivas y orientaciones. Se equivocan quienes asocian y reducen Trabajo Social Crítico solo con una tendencia existente en el Brasil de inspiración marxista, hoy existen otras tendencias críticas en el Trabajo Social que no son de inspiración marxista; el origen de esta orientación impartida es una conclusión a la que se llega en este seminario continental sobre la necesidad de continuar impulsando un proyecto profesional crítico en Trabajo Social que respondiera al contexto; desafortunadamente, ni el documento fue ampliamente difundido, ni se asimiló su aplicación por las diferentes unidades encargadas de la formación académica. Por Colombia participaron en este importante seminario los colegas Jesús Mejía, María Cecilia Tobón y Magdalena Barón.

Prospectiva. Revista de Trabajo Social e intervención social • No. $29 \bullet$ ene.jun. 2020 • pp. 01-38 e-ISSN: 2389-993X • Doi: 10.25100/prts.v0i29.8097

Universidad del Valle - Cali, Colombia 
de las realidades sociales concretas existentes, la imposibilidad de pretender adaptar a los seres humanos a una estructura social caduca y obsoleta.

Reflexionando sobre la condición y la viabilidad de la profesión en el contexto nacional, la propuesta del "Método Caldas" planteaba de manera original, y tal vez única al menos en nuestro país, que el camino que se debía comenzar a recorrer era el de la construcción del Trabajo Social como una ciencia social. Morales (1971) planteaba:

Concebimos la necesidad y urgencia de reflexionar sobre la realidad de nuestra sociedad y la viabilidad del trabajo social. No creemos como otros, que el trabajo social ha agotado su desarrollo y en razón de su inoperancia deba tender a su desaparición. Por el contrario, el análisis del trabajo social como teoría y como método y sus relaciones con la estructura social en donde se aplica nos ha mostrado el camino de la ciencia como el único camino factible y capaz de permitir su auténtico desarrollo. Es así como el trabajo social mientras siga en el plano del mero empirismo y manipulando técnicas sin una adecuada orientación teórica, y lo que es más grave, sin una práctica social que lo sustente, no encontrará el camino que le permita desarrollarse. Estancado y anticientífico, definitivamente, no tiene razón su existencia ${ }^{20}$. (pp. 4-5).

Esta postura, posteriormente en el contexto Latinoamericano y en el ámbito de la Reconceptualización a partir de 1971, contribuiría a la configuración de la llamada tendencia científica, que enfatizaba la perspectiva de la construcción del Trabajo Social como una ciencia social. Sin embargo, se debe subrayar que, en ese momento, no todos los estudiantes y profesores de Trabajo Social en el país entendían la trascendencia de este planteamiento, ya que se actuaba en un contexto bastante sobre-ideologizado, en el que permanentemente se cuestionaba la validez de este camino como alternativa para superar el dilema en que se encontraba el Trabajo Social; se criticaba por parte de algunos sectores estudiantiles radicalizados como una postura con un tinte puramente "academicista" y "cientificista".

El llamado era a superar una práctica empirista, descomprometida, neutra, sin embargo, este planteamiento lo que sugiere es que para justificar la existencia de un nuevo

${ }^{20}$ Según esta propuesta alternativa conocida como el "Método Caldas", la superación de la encrucijada existente a nivel del Trabajo Social en Colombia y Latinoamérica, se lograría al optar como salida por la construcción como una ciencia social, este según sus autores era el único camino factible y capaz de permitir su auténtico desarrollo. En este planteamiento no estaban equivocados, además, tuvieron el gran mérito de comenzar a vislumbrar en la medida en que insistían en la importancia de promover una praxis social, empezar a valorar de manera incipiente el papel de la investigación social aplicada en el campo de la profesión. Desde el Seminario Latinoamericano de Trabajo Social realizado en Ambato-Ecuador en 1971, los promotores del "Método Caldas" se convirtieron en los líderes indiscutibles en el ámbito de América Latina de esta tendencia científica, que sostenía que la encrucijada o el dilema, se lograría superar por la vía de articular la relación entre ciencia e ideología en una praxis transformadora de la realidad. Sobre el particular se señalaba "El objetivo del Departamento, es situar al estudiante en la ciencia, para esto se le brinda la teoría del conocimiento, buscando que capte los niveles de la formación de esta. La relación del conocimiento con la realidad social a través de la práctica social hasta llegar al conocimiento científico, momento en el cual el estudiante conoce la teoría de la ciencia y su objetivo e importancia transformadora, la clasificación y las relaciones con la sociedad, la cultura, la ideología y el compromiso social" (Morales, 1971, p. 21).

Prospectiva. Revista de Trabajo Social e intervención social • No. $29 \bullet$ ene.-jun. $2020 \bullet$ pp. 01-38 e-ISSN: 2389-993X • Doi: 10.25100/prts.v0i29.8097

Universidad del Valle - Cali, Colombia 
Trabajo Social, era necesario tomar como vía el camino de construirlo como una ciencia social aplicada, es decir, desarrollar y consolidar una formación fundamentada científicamente, que le permitiera a la profesión y a los futuros profesionales una práctica distinta en la realidad y a diferencia del resto de las demás Ciencias Sociales. A primera vista toda la sustentación teórica que se hacía en esta propuesta epistemológica y metodológica era atrayente y parecía razonable, en tanto que se optaba por un proyecto que intentaba articular una opción académica y política, al considerar que el Trabajo Social podría superar la encrucijada en que se encontraba si asumía el camino de promover su construcción como una ciencia social fundada en una construcción teórica y en una praxis social transformadora con una intencionalidad política.

Sin embargo, no era suficiente con enunciar las ideas para dar el salto cualitativo que se necesitaba, había que comenzar a recorrer el camino, el proceso más retador de abordar el conocimiento de la realidad aplicando una metodología de investigación social para comprender, interpretar y explicar la realidad social, articulando a la vez un método de conocimiento con un método de intervención para la transformación social. Allí, estuvo uno de sus mayores obstáculos o "cuellos de botella" e inconsistencias, como se verá más adelante, ya que las prácticas terminaron convertidas en su orientación y en su contenido condicionadas por referentes básicamente ideológico-políticos; sin embargo, hay que destacar que se aprendió a investigar haciendo investigación, este proceso tuvo un inmenso valor formativo para los estudiantes y profesores que participaban directamente de las experiencias. Tampoco es válido afirmar que al "Método Caldas" se le puede acusar de "cientificista", "academicista" como pretendieron algunos de sus más agudos críticos en su momento; al contrario, esta propuesta en su concepción y fundamentación intentó ligar conocimiento-acción, por tanto pretendió darle sentido a una praxis social transformadora de la realidad. No había antes en Colombia ninguna experiencia referenciada de este tipo, que intentara relacionar y articular un método de investigación con un método de intervención en la realidad para transformarla; sin duda esta propuesta tenía su originalidad pero era la vez un proyecto monumental que contenía enormes implicaciones y desafíos.

Esta propuesta metodológica o mejor esta teoría del conocimiento, que se puso en práctica incurrió en un grave desfase en la articulación creativa que se requería, al pretender integrar en la praxis la aplicación de estos dos métodos en la realidad. En esta propuesta se sobredimensionaba la práctica y la necesidad de un conocimiento de la realidad microsocial para producir y clarificar conceptos como acercamiento progresivo partiendo de la reeducación de los sentidos (Ver, oír, sentir y recordar) para poder escribir los diarios de campo temáticos; sin embargo, no se le da la misma importancia al conocimiento de la realidad macroestructural, ésta casi siempre era definida a-priori o simplemente se ignoraba, bajo la premisa que los conceptos tenían que emerger e irse construyendo en el contexto de la realidad particular para luego ligarla en un segundo momento al conocimiento de la realidad macroestructural.

Sin embargo, cuando se aplicaba el proceso metodológico en sus dos momentos primer momento, que permitiera la ubicación y situación en una comunidad (geográfica o funcional); segundo momento, establecer la relación entre conocimiento-acción para lograr el conocimiento de la estructura social esto no se lograba y además la iniciación del proceso de intervención quedaba reducido a una práctica educativa de concientización. Allí 
comenzó la mayor dificultad porque el conocimiento social generado en el proceso de comprender el ámbito de las micro-realidades y las condiciones sociales de existencia que caracterizaban la vida de las poblaciones, no eran objeto tampoco de una sistemática reflexión y construcción social, que sirviera de sustentación a la intervención profesional; toda esta riqueza de la información y del conocimiento social construido se esfumaba. De hecho la intervención quedaba siempre en este contexto reducida a la iniciación y desarrollo de un proceso educativo, orientado a promover la concientización y la acción organizada de las comunidades; en esas condiciones el papel del Trabajo Social quedaba limitado a convertirse en lo fundamental en un educador social y en un agente promotor del cambio social.

En este sentido no había una clara comprensión sobre las implicaciones que tenía en la realidad la aplicación del método de intervención, en tanto que no había tampoco claridad respecto a la necesaria distinción entre investigación teórica e investigación aplicada y la importancia de esta última para la intervención social profesional. En esta propuesta el método de intervención en la realidad queda reducido o circunscrito a cumplir una función educativa liberadora; la intervención especifica del Trabajo Social desaparece por completo, en tanto que tampoco se recibe en el currículo una formación fundamentada en teorías del Trabajo Social renovadas, que diera herramientas teórico-conceptuales y metodológicas para la intervención profesional, como se puede constatar al examinar la estructura curricular de la época ${ }^{21}$.

El "Método Caldas" era fundamentalmente una metodología para el conocimiento de la de la microrealidad que buscaba el cambio social promoviendo una acción educativa y política; sin embargo, la intervención profesional específica en la práctica se descartó y en la formación académica se dejaba de lado la enseñanza de los métodos clásicos, la metodología clásica, el método polivalente, el método integrado, incluso, las llamadas "metodologías de transición", que se venían promoviendo en algunos países del Cono Sur, como eran las propuestas de Método Básico y Método Único; de hecho se opta por una “Metodología

${ }^{21}$ Para ilustrar esta situación tomar en cuenta la estructura del nuevo plan de estudios que se empezó a aplicar en el año de 1969. Esta estructura curricular estaba fundamentada en la "Metodología del Trabajo Social para la acción transformadora" de la realidad. En cuanto al proceso metodológico del Trabajo Social se iniciaba con: 1. Fundamentación científica en ciencias sociales que incluía: filosofía, sociología, economía, política, antropología, historia social y política, biología, ecología y teoría general del derecho civil; 2. El proceso metodológico y la teoría del conocimiento. Esta metodología propuesta respondía en la estructura curricular a dos momentos: a) La Ubicación. Implicaba un proceso mediante el cual el trabajador social se acerca y se sitúa en la comunidad (geográfica y funcional), en actitud científica para el conocimiento de su estructura física y social, con unos objetivos específicos; b) La relación y la acción. Tenía por objeto el conocimiento de la estructura social de la comunidad y la iniciación del proceso de educación concientizadora. En cuanto a la dosificación de los contenidos referentes al área de la metodología, esta estaba estructurada en seis semestres. En los dos primeros semestres el estudiante recibía información teórica sobre Historia del Trabajo Social y teorías del Trabajo Social, los cuales se articulaban a los desarrollos de los contenidos de los cursos de Metodología con una duración de seis semestres. Se iniciaba en el tercer semestre simultáneamente los cursos de metodología con las prácticas hasta el octavo semestre en que terminaba el ciclo de formación en un período de cuatro años. Sin embargo, hay que precisar que los contenidos de los cursos de metodología enfatizaban contenidos relacionados con fundamentación epistemológica, teórico-conceptual y metodológica de la investigación social (Morales, 1971, pp. 2132).

Prospectiva. Revista de Trabajo Social e intervención social • No. $29 \bullet$ ene.-jun. $2020 \bullet$ pp. 01-38 e-ISSN: 2389-993X • Doi: 10.25100/prts.v0i29.8097 Universidad del Valle - Cali, Colombia 
Alternativa" para el conocimiento y la acción transformadora de la realidad social con una clara finalidad política.

En este sentido Morales (1971) planteaba:

(...) solo así se podrá participar en el proceso de educación concientizadora, utilizando sistemas de organización, motivando el cambio basado en el análisis de acción de las organizaciones, planeando y administrando, para conseguir de esa manera una movilización comunitaria en razón de objetivos concretos. (p. 17).

De esa manera esta propuesta metodológica, al aplicarse en la realidad, terminaba sobredimensionando la educación concientizadora para promover la acción política organizada, reduciendo la acción profesional a una acción educativa social orientada a promover un proceso de toma de conciencia crítica por parte de la comunidad, que le permitiera transformar su conciencia "ingenua" o "alienada" de la realidad en una conciencia crítica que la potenciara a la acción y al cambio social.

El énfasis estaba en conocer la realidad para promover la concientización, en ese contexto la acción profesional quedaba limitada al uso de algunas técnicas para uniformar, generalizar datos y procedimientos que servían para hacer análisis y planteamientos sobre realidades concretas. En esa perspectiva la propuesta incurre en una postura rígida, ortodoxa ya que sobredimensionaba una función política-educativa para promover el cambio social, colocando en un segundo plano el uso que se podía hacer del conocimiento social, para construir la intervención social profesional específica y responder adecuadamente a las necesidades, problemas y problemáticas sociales planteadas por la población en la cotidianidad. Este desfase tendría graves implicaciones en términos teóricometodológicos, ya que no se pudo en ese momento tener una claridad meridiana para formular la relación que podía aportar la articulación de un método de conocimiento para abordar la realidad, con la aplicación de un método de intervención para el cambio y la transformación, que no descartara la intervención específica del Trabajo Social.

Esta propuesta metodológica tenía indudablemente su propia lógica, pero cuando se abordaba la fundamentación teórica en términos de las teorías sociales correspondiente a los contenidos curriculares de los programas que constituían el plan de estudios, se enfatizaban distintas fuentes teóricas: teoría del cambio social, teorías del desarrollo y teorías críticas sobre el subdesarrollo, teorías de la dependencia, teoría de la concientización de Freire, una concepción teórico-teológica de la liberación, y una teoría marxista (materialismo histórico y dialéctico), no faltaron tampoco lecturas e interpretaciones teóricas cristianas del marxismo; el resultado fue una postura no exenta de contradicciones, cayendo muchas veces en una especie de eclecticismo, que intentaba conciliar lo que de hecho no era conciliable en términos epistemológicos.

Desde el punto de vista metodológico se sobredimensionaba una teoría del conocimiento para abordar las microrelidades, ya que en términos de la investigación social concreta, ésta se reducía a la aplicación de una metodología sin método como enfatizaba el "Método Caldas", el cual comenzaba en su aplicación por un trabajo de "reeducación de los sentidos" como criterio fundamental para insertarse en la realidad, lo demás, era

Prospectiva. Revista de Trabajo Social e intervención social • No. $29 \bullet$ ene.-jun. $2020 \bullet$ pp. 01-38 e-ISSN: 2389-993X • Doi: 10.25100/prts.v0i29.8097

Universidad del Valle - Cali, Colombia 
considerado como anticientífico 22 . Así las prácticas paulatinamente fueron perdiendo su carácter académico, en la medida que se transformaron progresivamente asumiendo en su contenido un carácter ideológico-político; se actuaba inspirado en promover procesos de concientización, organización y movilización. Los que tuvimos la oportunidad de participar de manera directa en esta experiencia sentíamos que estábamos transformando el mundo, actuábamos imbuidos de un profundo altruismo, fundamentado en el compromiso con los pobres. Estábamos, además, convencidos de que se estaba construyendo un Trabajo Social Liberador.

Tal vez el aspecto positivo de estas prácticas llevadas a cabo en esta perspectiva metodológica tuvo que ver con la emergencia de una serie de problemas, que se tradujeron en el surgimiento de varios interrogantes que siempre aparecían en los debates, reflexiones y discusiones que sosteníamos en ese momento, por ejemplo: ¿Qué se debía entender por construir una ciencia social y cuáles eran sus implicaciones? ¿Qué era una praxis social?, ¿Cuál era la relación y la diferencia entre el método y la metodología de investigación?; pero también, ¿Qué se debía entender por métodos y metodologías de intervención profesional? ¿Cuál era la diferencia existente entre investigación teórica e investigación aplicada? ¿Cuál era la importancia de la investigación aplicada para construir la intervención profesional en el Trabajo Social? ¿Cuáles eran los fundamentos de la metodología clásica del Trabajo Social? Nuestras prácticas generaron conocimiento para la acción política, pero hubo un limitado uso de la investigación social aplicada que generaba conocimiento social para sustentar la intervención profesional específica, que permitiera ir renovando marcos de referencia creativos, que se tradujeran en una nueva práctica profesional en el contexto de la época.

Hay que anotar que en el contexto de la Reconceptualización que se produjo en América Latina, surgen posteriormente dos tendencias diferenciadas en torno al asunto de los métodos y las metodologías de intervención. La primera, que se puede clasificar como "Metodologías de Transición", comprende las siguientes propuestas: método integrado, método polivalente, método básico y el método único. En esta perspectiva más allá de las críticas que se les pueda hacer a estas propuestas metodológicas, algunas de ellas planteadas por Lima (1975), en el sentido de que no están exentas de una carga positivista, de su discutible funcionalidad en su aplicación práctica, de la desaparición formal o nominal de lo que venían siendo los objetos de acción de los métodos clásicos: individuo, grupo, comunidad creyéndose así simplificar y hacer más científico el quehacer profesional. Hay que reconocer que esta propuesta se constituyó en el primer esfuerzo genuinamente Latinoamericano, que intentó dotar al Trabajo Social de la formulación de un método general, que le diera un nuevo sentido, por lo tanto un mayor sobredimensionamiento a la

${ }^{22}$ Es necesario precisar que los demás métodos de investigación social eran considerados como anticientíficos, ya que se planteaba desde una postura dogmática y puramente sobre-ideologizada que hacían parte de la llamada ciencia burguesa; desde esta perspectiva, se reconocía como únicamente científico el llamado método materialista-dialéctico e histórico, el cual tampoco se aplicaba de manera rigurosa, postura que aún hoy se continúa sosteniendo en la contemporaneidad por parte de una de las tendencias existentes.

Prospectiva. Revista de Trabajo Social e intervención social • No. $29 \bullet$ ene.jun. 2020 • pp. 01-38 e-ISSN: 2389-993X • Doi: 10.25100/prts.v0i29.8097

Universidad del Valle - Cali, Colombia 
intervención colectiva sobre la intervención individual, en un contexto estructural completamente diferente del existente en los países desarrollados ${ }^{23}$.

De esta manera, las distintas iniciativas que hicieron parte de la denominada "Metodologías de Transición", intentaron dejar de lado los métodos tradicionales o clásicos, retomaron los llamados métodos propiciatorios o auxiliares: planeación social, administración social, investigación y supervisión, convirtiéndolos en los referentes centrales del intento de re-fundamentación teórico-metodológica de estas nuevas propuestas. Hay que reconocer la intencionalidad de este esfuerzo por tratar de abordar el estudio de lo social bajo nuevas perspectivas teóricas y metodológicas, rompiendo así con las concepciones anteriores que venían condicionando la práctica del Trabajo Social en América Latina, la cual reducía la intervención profesional al simple ajuste, adaptación, corrección de las disfuncionalidades sociales. Este esfuerzo que fue meritorio, que abrió nuevas perspectivas teórico-metodológicas para repensar la formación y la intervención profesional bajo nuevos horizontes, de alguna manera este proceso se truncó, se fue desvirtuando paulatinamente por el impacto de la tendencia más radical de la Reconceptualización que, orientándose en una postura política-ideológica, tuvo como expresión y escenario la Región Andina: Colombia, Bolivia, Ecuador, Perú y Venezuela.

La segunda tendencia enmarca las denominadas "Metodologías Alternativas" para la acción transformadora de la realidad, en la cual se agrupan las siguientes propuestas: Metodología del Trabajo Social para la acción transformadora o "Método Caldas" (Colombia), Método de Intervención en la Realidad (Bolivia), Modelo de Intervención en la Realidad "MIR" (Venezuela). Todas estas propuestas tienen en común el esfuerzo por tratar de fundamentar la articulación de un método de conocimiento con un método de intervención en la realidad, pero soslayaron la discusión sobre los fundamentos teóricoconceptuales y metodológicos del quehacer o de la intervención profesional. Mientras en el Cono Sur se avanzaba en la búsqueda por repensar la intervención profesional asumiendo la reflexión sobre el asunto de los métodos y la metodologías de intervención, partiendo de reconocer el contexto y de construir una conceptualización de lo social, en la Región Andina florecían las propuestas alternativas metodológicas, que sobredimensionaban la acción política para la acción transformadora de la realidad, empeñadas fundamentalmente en el cambio radical de las macro-estructuras sociales y en el proyecto de emancipación humana de los oprimidos.

Superada en parte la encrucijada del Trabajo Social en el caso de Colombia, este proceso tuvo repercusiones negativas, por lo menos en términos de la formación profesional, porque el radicalismo vivido durante este período generó una especie de rechazo inconsciente, donde el interés por la discusión teórico-metodológica pasa

${ }^{23}$ Eroles (2005) define el método "como el conjunto de procedimientos ordenados que guían la acción profesional para conocer y transformar la realidad. Supone operaciones que permiten concretar estas funciones a través de una práctica social intencionada. En síntesis, el método actúa como un facilitador del conocer para la acción, donde a través de aproximaciones sucesivas, logramos un conocimiento cada vez mayor del objeto y una acción transformadora más eficaz" (pp. 126-128). Mientras que el método es una carta de navegación o mejor un camino, por metodología se puede entender el desdoblamiento de los métodos en la realidad.

Prospectiva. Revista de Trabajo Social e intervención social • No. 29 • ene.-jun. 2020 • pp. 01-38 e-ISSN: 2389-993X • Doi: 10.25100/prts.v0i29.8097

Universidad del Valle - Cali, Colombia 
definitivamente a un segundo plano durante la década de los ochenta, sin lograr darle salida a muchos de los problemas relacionados con la formación académica, pero puntualmente con la intervención profesional ${ }^{24}$. Las unidades académicas de Trabajo Social se dedican unas a la enseñanza de los llamados métodos tradicionales, otras plantean la necesidad de orientar la formación por la integración de estos métodos; un último grupo, introduce cambios derivados de las propuestas del método básico, del método único, orientando la enseñanza de las metodologías de intervención por procesos integrados. Sería muy interesante analizar cuál fue el aporte de esta tendencia, sus principales limitaciones para el desarrollo profesional. Este tipo de investigación está por hacerse en nuestro medio ${ }^{25}$.

\subsection{Principales cuestionamientos al "Método Caldas"}

De hecho, Barreix otro miembro destacado de la "Generación del 65", se convirtió en ese momento histórico en uno de los más duros críticos del denominado "Método Caldas", catalogándolo como la "línea populista" del proceso de Reconceptualización. Aunque no logra desarrollar una argumentación coherente y bien fundada, apela por el contrario, de manera reiterada, al uso de una serie de descalificativos que evidencian el clima de polarización ideológica que se daba en el momento. En esta dimensión Barreix y Castillejos (2003) señalan:

Importa por lo tanto destacar que lo que originalmente fue el "Método Caldas", a través de sus múltiples versiones y formas de presentación, causó verdaderos estragos dentro del proceso de Reconceptualización del Trabajo Social por muchas razones, entre las que cabe citar a manera de ejemplos:

a. La difusión masiva, fuertemente financiada, que recibió por parte de la Fundación (Konrad Adenauer) y de otras organizaciones demócrata cristianas y socialdemócratas (...) que incluyeron reiterados (desplazamientos) por todo el continente para sus principales exponentes.

b. La engañosa terminología pseudo-marxista usada en su exposición que se convirtió en una peligrosa trampa para incautos, muchos incluso de buena fe, $y$;

c. La pretensión explícitamente sostenida por los autores de algunas de sus versiones de que, en cierta forma, muestra un paralelismo en sus etapas con el método científico

${ }^{24}$ En ese período, el primer seminario sobre sobre "Formación metodológica en Trabajo Social" se realizó en Colombia en 1979. El Consejo Nacional para la Educación en Trabajo Social CONETS emprendió una investigación sobre la formación metodológica del trabajador social a través de un proyecto de capacitación-investigación apoyado por el CELATS y coordinado por Victoria Eugenia Muñoz y José Adán Guzmán de la Universidad de Antioquía. Las ponencias presentadas por profesores de las distintas unidades académicas fueron sustentadas en el Encuentro nacional realizado en la Universidad Pontificia Bolivariana de Medellín, posteriormente estos trabajos fueron publicados en Cuadernos Celats $\mathrm{N}^{\circ} 22$, Lima, Perú, 1979. El segundo seminario nacional en "Metodologías de intervención profesional" fue realizado treinta años después en la Universidad de Antioquia en Medellín en el 2009 promovido por el CONETS, era tanto el desconocimiento y la falta de memoria histórica que cuando la junta directiva convocó al evento pensaban que estaban realizando el I Seminario Nacional sobre este tema.

${ }^{25}$ Una de las pocas evaluaciones críticas sobre esta corriente, ha sido realizada específicamente en contra del "Método Caldas" por Barreix y Castillejos (2003), en el texto Metodología y Método en Trabajo Social, denominándola como la "línea populista" del proceso de Reconceptualización.

Prospectiva. Revista de Trabajo Social e intervención social • No. 29 • ene.-jun. 2020 • pp. 01-38 e-ISSN: 2389-993X • Doi: 10.25100/prts.v0i29.8097

Universidad del Valle - Cali, Colombia 
concreto-abstracto-concreto que propone la teoría materialista del conocimiento. Además, para completar el panorama se sumó la pretensión de algunos de sus autores, sostenedores y propiciadores, de que no se trataba de un mero "método" de Trabajo social o de un trabajo social comunitario, sino de toda una "metodología", con todas las implicaciones que esto tiene, desde el punto de vista epistemológico (...) Tal es así, que sobre su base (y la de nuevas modificaciones formales), hubo quienes pretendieron "fundar" una "Epistemología para el Trabajo Social" 26. (Barreix y Castillejos, 2003, pp. 36-53).

Sin embargo, llama la atención que estos autores refiriéndose al tema sobre epistemología, método y metodología (Barreix y Castillejos, 2003) destacan:

en el ámbito del trabajo social ha primado una confusión extrema, muy especialmente en el denominado "trabajo social reconceptualizado", la que no ha sido salvada hasta el presente excepto rarísimas excepciones los únicos que tenían clara esta distinción entre método y metodología eran los autores del "Método Caldas.

Al respecto, es necesario señalar la aclaración que hacen Barreix y Castillejos (2003) refiriéndose al "Método Caldas", cuando señalaban que los autores de esta propuesta en su momento establecían claramente la diferencia entre método y metodología. “El metodólogo colombiano (Antropólogo) Manuel Zabala y, obviamente sus discípulos y seguidores, son prácticamente los únicos que han marcado esta diferencia fundamental desde el punto de vista epistemológico y gnoseológico, en el ámbito del trabajo social (Barreix y Castillejos, 2003, p. 39).

La otra mirada la introduce Faleiros (2003) al plantear que el "Método Caldas" sobredimensiona la práctica, pero también se constituye en una tendencia que en ese momento histórico reivindica una metodología sin método:

una de las propuestas invirtió el esquema tradicional del planeamiento o, mejor, planteo "una metodología sin método" (Zabala, 1974), para llegar a la población por medio de una dinámica de "desconocimiento", esto es, de abolición de las categorías globales para sumergirse en lo local (ubicación) a través de la práctica, a fin de que fueran surgiendo allí los conceptos apropiados. Esta supervalorización de la práctica y de la base partía de una estrategia militante junto al pueblo, cuestionando el formalismo, pero defendiendo el vanguardismo y el espontaneísmo sin la conciencia de una construcción teórica. (Faleiros, 2003, p. 96-97) ${ }^{27}$.

${ }^{26}$ Estos autores se refieren a la propuesta sobre el "Modelo de Intervención en la Realidad" elaborado por la Universidad Central de Venezuela, el cual está incluido en el libro publicado por Lima (1975) Epistemología del Trabajo Social, Argentina: Editorial Hvmanitas.

27 Faleiros (2003) muestra como "el debate sobre la relación teoría/práctica atraviesa el movimiento de Reconceptualización de forma fecunda, y en él se sitúa la cuestión metodológica. El rechazo del teoricismo por la práctica, en algunos casos, desechó también la teoría, o sea, al niño con el agua del baño" (Faleiros, 2003, p.97). Relativizo la interpretación de este autor, ya que considero que los promotores del "Método Caldas", si tenían conciencia de la necesidad de la teoría y ello se refleja en la formulación de ligar conocimiento/ acción y en su propuesta de construir el Trabajo Social como una ciencia social, que debe producir conceptos a partir del conocimiento de la microrealidad social y que debía ser ligado al conocimiento de la realidad macroestructural. Sin embargo, su crítica es acertada en términos que dejaban de lado el uso de categoría globales; el que

Prospectiva. Revista de Trabajo Social e intervención social • No. $29 \bullet$ ene.-jun. $2020 \bullet$ pp. 01-38 e-ISSN: 2389-993X • Doi: 10.25100/prts.v0i29.8097

Universidad del Valle - Cali, Colombia 
En parte retomados los aciertos y superadas las frustraciones por los primeros fracasos se fue logrando paulatinamente a partir de una reflexión crítica avances significativos en su refundamentación, que promovieron algunos sectores comprometidos en la necesidad de continuar aportando a su construcción profesional-disciplinar. Por esta razón, es tan importante hoy en día, seguir promoviendo la reflexión sobre los procesos metodológicos de intervención en lo social y en su fundamentación epistemológica, ontológica, teóricoconceptual, técnico-operativa y ético-política, y, de manera particular profundizar sobre los fines y objetivos de la profesión en el contexto Latinoamericano; por supuesto, sin dejar de lado los referentes de identidad profesional relacionados con su origen y fundamentación como profesión-disciplina. Sin embargo, hay que destacar que en este proceso de la posreconceptualización en que nos encontramos, se han venido produciendo avances significativos en su consolidación como práctica profesional y en su construcción disciplinar en Colombia y en otros países de América Latina.

\section{El debate en torno al Trabajo Social como integrador de las Ciencias Sociales}

La discusión que se origina por la inclusión de la formación académica de Trabajo Social en el ámbito universitario y su papel como el mejor "Laboratorio de integración de las Ciencias Sociales", dio lugar a los más apasionados debates durante esta época. Esta aguda confrontación generó consideraciones y valoraciones absurdas de representantes de otras profesiones y disciplinas, quienes se dedicaron a cuestionar y a poner en tela de juicio su origen y su papel como profesión y a rechazar su inclusión académica, por considerarla inconveniente y negativa para los intereses del pueblo colombiano.

Estos críticos, incluso desconociendo sus propios debates internos, partían también de ignorar e invisibilizar la existencia en el ámbito de la profesión de la confrontación radical que se venía dando entre dos tendencias: de un lado, los defensores de un Trabajo Social tradicional, conservador, adaptador e instrumentalista, que enfatizaba la neutralidad y la "asepsia metodológica" y el "individualismo metodológico"; de otro lado, los promotores de una tendencia que venía intentando redefinir la profesión en una perspectiva progresista y empeñados en el cambio y la transformación social de la realidad. Sin embargo, hay que plantearlo, esta segunda tendencia comenzó expresándose en Colombia como una corriente minoritaria en su momento, pero eso sí bastante radicalizada desde el punto de vista ideológico-político, la cual fue ganando audiencia gradualmente y un mayor posicionamiento en la formación académica. Las tensiones y las profundas diferencias vividas entre las dos tendencias en el conjunto de las unidades académicas durante este período, hicieron imposible durante los primeros años de su institucionalización de la formación académica en el campo universitario, definir y unificar en el ámbito nacional unos criterios mínimos para orientar la formación académica de Trabajo Social en el país ${ }^{28}$.

no se haya alcanzado en ese momento un conocimiento articulado entre realidad microestructural y macroestructural va a depender en parte a las concepciones heterogéneas en juego y a los caminos metodológicos tomados en el desarrollo de las múltiples experiencias.

${ }^{28}$ Esta orientación empezó a ser posible a partir de 1976 cuando el Instituto Colombiano para el Fomento de la Educación Superior (ICFES) convoca a la constitución de un Grupo de Trabajo Académico (G.T.A) el cual será integrado por representantes de los programas académicos de Trabajo

\footnotetext{
Prospectiva. Revista de Trabajo Social e intervención social • No. $29 \bullet$ ene.jun. $2020 \bullet$ pp. 01-38 e-ISSN: 2389-993X • Doi: 10.25100/prts.v0i29.8097

Universidad del Valle - Cali, Colombia
} 
En este sentido Corredor (1972) uno de los más agudos críticos y opositores a la inclusión del programa de Trabajo Social en la Universidad Nacional sostenía:

La carrera de Trabajo Social surge de las necesidades de un país o países en donde los factores económicos, políticos y sociales en conjunto son cualitativamente diferentes a los de una realidad como la colombiana. Consecuente con lo anterior y dentro del carácter de unidad y relación teórica-práctica que el conocimiento implica, el trabajo social pretende mantener las relaciones existentes en la sociedad, es decir, el sistema establecido que fundamenta y explica su existencia, a cambio de los paliativos que pueda ofrecer en la práctica de adaptar al medio a individuos descarriados o víctimas de una sociedad. En el caso de Colombia, la carrera de Trabajo Social en su teoría como en su práctica, en su esencia como en su forma, además de innecesaria llega a ser negativa a las aspiraciones del pueblo colombiano, el cual busca romper la dependencia económica, política, social y cultural como requisito indispensable para el cambio en la sociedad. En síntesis, los intereses populares colombianos y los intereses del Trabajo Social objetivamente analizados, están en contradicción, irreconciliablemente por la base.

Tal vez, en lo único que tenía razón este cuestionamiento que se hace de la profesión, es que ella surge como el resto de todas las demás Ciencias Sociales también en otro contexto económico, político, social y cultural cualitativamente distinto al contexto colombiano. En cierto sentido se parte de una premisa parcialmente cierta la cual aplica para el Trabajo Social, pero no para el resto de las ciencias sociales; además, ignora deliberadamente en ese momento socio-histórico, la existencia de dos tendencias opuestas en el ámbito del Trabajo Social. Una de la cuales enfatizaba la necesidad de comprender e interpretar los conflictos sociopolíticos que se producían en nuestra sociedad, propiciando una formación que permitiera luego desarrollar un tipo de intervención profesional cualitativamente distinta.

Sin embargo, este autor parte de confundir el carácter de las Ciencias Naturales con las Ciencias Sociales, en este sentido es necesario comenzar por precisar que en sus orígenes y en su constitución estas últimas fueron influenciadas por el organicismo, el naturalismo y el positivismo, que por la vía de las analogías algunos autores como Spencer, Comte, Durkheim, Talcott Parsons y Merton pretendieron desarrollarlas a su imagen y semejanza desde el punto de vista epistemológico, teórico, metodológico al pretender encuadrarlas en el llamado "método científico" o método experimental o en los enfoques cuasiexperimentales de las ciencias duras o exactas. Esta es la base de la concepción que asumieron para la época muchos de los autodenominados "científicos sociales" en nuestro medio, quiénes actuando como depositarios o en representación de sus disciplinas, se

Social existentes en el país, que habían sido incorporados en las principales universidades públicas y algunas privadas de Colombia. Esta comisión estuvo integrada por: Antonio Puerta y José Adán Guzmán por la Universidad de Antioquia; Jesús Mejía, Carmen Lucia Giraldo por la Universidad del Valle; Mario González y Víctor Mario Estrada por la Universidad de Caldas; Juan Manuel Latorre, Perla Amanda Ruiz por la Universidad Industrial de Santander; Fanny Rubio, Morelia Martínez por la Universidad Externado; María Eugenia Martínez, Yolanda Puyana por la Universidad Nacional de Colombia, y por delegados de la Universidad de Cartagena; en representación del ICFES participó el sociólogo Jaime Zuluaga como coordinador académico. Este grupo de académicos tuvo como tarea definir y proponer primero unos criterios que se tradujeron en la formulación de una propuesta de "plan mínimo" de estudios, que unificó la formación académica curricular en Trabajo Social a nivel nacional.

Prospectiva. Revista de Trabajo Social e intervención social • No. $29 \bullet$ ene.jun. $2020 \bullet$ pp. 01-38 e-ISSN: 2389-993X • Doi: 10.25100/prts.v0i29.8097

Universidad del Valle - Cali, Colombia 
empeñaban fundamentalmente en defender su preocupación por la construcción de su estatus teórico y su legitimidad científica, reduciendo su papel a la construcción del conocimiento por la vía de la confrontación entre teoría y empíria, manteniendo como postura hegemónica su indiferencia moral y ética y una actitud contemplativa frente a la realidad social 29 .

En general todas las profesiones y disciplinas de las llamadas Ciencias Sociales y Humanas han sido históricamente un campo de debate y de combate, en que se han confrontado tendencias conservadoras que enfatizan el control y el mantenimiento del orden social, y tendencias progresistas que han promovido el cambio y la transformación social. Olvidaban los defensores de estas tesis que el origen y desarrollo de las Ciencias Sociales en Latinoamérica ha sido fiel copia de los desarrollos positivistas y del funcionalismo-estructural que se introdujo como pensamiento hegemónico en el mundo occidental, lo cual también generó en su tiempo una profunda reacción intelectual que se expresaba en contra del neocolonialismo existente en el campo del conocimiento.

El problema consistía en que la Universidad colombiana de aquella época, por su carácter y condición, por el tipo de enseñanza que impartía, sí estaba en contradicción irreconciliable por la base con los propósitos y aspiraciones del pueblo colombiano, en cuanto ésta no interpretaba científicamente esa realidad y tampoco promovía su transformación; de hecho, los contenidos curriculares no daban cuenta del contexto y de las condiciones de vida y de existencia de la población. En la práctica, el carácter, la función de la educación y en particular de la Universidad de aquel tiempo, lo que asumía era la defensa del orden social imperante. Este es un problema central que se plantea el movimiento estudiantil universitario nacional de la época, al cuestionar el papel que cumplía la Universidad en el contexto de la sociedad en términos de la formación, la investigación y la extensión.

En la historia de la humanidad, las grandes revoluciones o transformaciones totales de la sociedad la han hecho los pueblos, siendo actores de primer orden los partidos, los movimientos políticos o sociales, en la realización de estos procesos de transformación política, económica, social, cultural e institucional etc.; en ese contexto la Universidad, las profesiones y disciplinas no se pueden asimilar a partidos o movimientos políticos y sociales, lo que pueden y deben hacer es contribuir a promover procesos de cambio social y transformaciones parciales de la realidad social y deben en el contexto nuestro promover

${ }^{29}$ En este sentido Corredor (1972) coloca en un mismo plano todas las ciencias, reduce su cientificidad a la utilización del "método experimental" (Método científico), confunde al mismo tiempo los aportes de los grandes científicos de la naturaleza y de la sociedad surgidos en el curso de la historia. Ciertamente, un Copérnico, Bruno, Galileo, Newton, Darwin, Marx, Freud y un Einstein no nos llegaron de otro planeta, ni de otra dimensión desconocida, pero las Ciencias Sociales y Humanas no se pueden confundir con las Ciencias Naturales, máxime cuando en nombre del poder, de ciertas posiciones ideológico-políticas algunas de estas teorías han sido negadas, algunas además, proscritas incluyendo por supuesto sus autores siendo muchos de ellos perseguidos e invisibilizados en el curso de la historia; entre otras razones, porque tuvieron el gran mérito de poner en entredicho, muchas de las teorías e ideologías existentes, que en algunos casos se construyeron a nombre del poder, de la ciencia o de la religión como verdades absolutas.

Prospectiva. Revista de Trabajo Social e intervención social • No. $29 \bullet$ ene.jun. $2020 \bullet$ pp. 01-38 e-ISSN: 2389-993X • Doi: 10.25100/prts.v0i29.8097

Universidad del Valle - Cali, Colombia 
procesos emancipatorios o por el contario oponerse asumiendo la defensa del orden social imperante.

Corredor (1972) asume que las Ciencias Sociales se caracterizan por la unidad teóricopráctica que la construcción del conocimiento implica y que éste en su esencia está garantizado, al asimilar estas a las Ciencias Naturales y al método científico experimental; si así fuera no tendría ninguna validez que en ese momento se las criticara justamente porque pretendían construir un conocimiento social despreocupándose de tomar estos problemas sociales como referentes para la acción social. Esta situación lo que evidenciaba era el carácter de "alienación" y de "colonización intelectual" al que habían llegado en nuestro medio algunos "científicos sociales", ya que no apreciaban que el positivismo y el funcionalismo-estructural, son teorías y métodos que aplicados no explican integralmente los fenómenos que se producen en la sociedad, que encubren la realidad, puesto que no descubren las relaciones internas, no explican la asociación estructural causal, ni los fenómenos dentro de un contexto donde existen, desigualdades sociales diversidad de clases, grupos, etnias y géneros con marcadas diferenciaciones sociales y culturales.

El que las Ciencias Sociales estén en construcción en América Latina, es el producto del cuestionamiento crítico, del análisis logrado de las relaciones sociales que rigen estas sociedades; esta situación evidencia que estas están realmente por constituirse y por desarrollarse. Uno de los más importantes debates de la época, como se ha planteado anteriormente, giraba alrededor del cuestionamiento crítico que se hacía en general a las Ciencias Sociales ${ }^{30}$. De allí que, en el contexto de la Reconceptualización, al incorporar la noción de praxis social, entendida ésta como la relación dinámica y dialéctica entre conocimiento-acción, se llegó a considerar por parte de quienes compartían las ideas de esta tendencia, que esta profesión era el mejor "Laboratorio de las Ciencias Sociales para lograr su integración", dada su clara intencionalidad práctica. En esa perspectiva se fueron construyendo y asumiendo varias posturas; una, que colocaba al Trabajo Social como profesión en una relación de dependencia y sumisión frente al conjunto de las Ciencias Sociales; otra, que consideraba que dada su intencionalidad práctica le permitía potenciar la integración de las teorías sociales en la acción.

La crítica formulada por Corredor (1972) es enfrentada por el Claustro de profesores y estudiantes de Trabajo Social de la Universidad Nacional de Colombia (1972) sosteniendo la siguiente tesis: "Es al trabajador social a quien corresponde realizar la integración entre la teoría y la práctica, basados en el método científico y con las teorías que aportan las diferentes Ciencias Sociales". Esta postura para la época era asumida por algunos sectores del Trabajo Social. Sin embargo, hay que señalar que quienes defendían esta posición no eran muy conscientes, ni tenían mayores claridades comprensivas desde el punto de vista

30 Sobre este tema es importante referenciar el Texto de Zuleta (1999). En su presentación se afirma: esta conferencia data de Julio de 1978 y fue pronunciada originalmente delante de un auditorio repleto, atento al discurrir de este cautivante maestro quién con sencillez y persuasiva dialéctica, problematizó la relación entre valores y hechos en las ciencias sociales, la literatura y las artes, un tópico que no pierde actualidad, rastreando su esencia y sus nexos con la ideología y examinando la singularidad de los saberes sociales en contraste con las ciencias naturales (Zuleta, 1999, pp. 1-2).

Prospectiva. Revista de Trabajo Social e intervención social • No. $29 \bullet$ ene.-jun. $2020 \bullet$ pp. 01-38 e-ISSN: 2389-993X • Doi: 10.25100/prts.v0i29.8097

Universidad del Valle - Cali, Colombia 
epistemológico, teórico-conceptual y metodológico sobre las diferencias existentes entre las Ciencias Naturales y las Ciencias Sociales, los distintos tipos de investigación social (cualitativa y cuantitativa), reduciendo el conocimiento de la realidad a la aplicación del llamado "Método científico" tampoco tenían una adecuada comprensión sobre el desigual desarrollo y características de las diferentes profesiones y disciplinas. Se ignoraba además, desde una postura hasta cierto punto ingenua, que en las Ciencias Sociales existentes en nuestro medio predominaba un enfoque fundamentalmente positivista y funcionalistaestructural, lo cual problematizaba y era sin duda alguna un serio obstáculo para lograr la integración teórico/práctica.

La contra-réplica se formuló en términos más fuertes por parte de Corredor (1972) al afirmar:

Lo anterior, presentado en un intento de justificar la existencia del Trabajo Social en la Universidad, descansa claramente sobre una base inconsistente desde el punto de vista científico. Suponen los defensores del Trabajo Social que la teoría y la práctica son partes desintegradas y que debe haber alguien que las integre y ese alguien es nada menos que el trabajador social (...) Los grandes científicos de la naturaleza y la sociedad que han surgido en la historia, ciertamente no nos han llegado de otro planeta o de una dimensión desconocida, sino que por el contrario, han surgido, se han desarrollado y han podido practicar sus conocimientos gracias a la realidad de donde adquirieron dichos conocimientos, y a la base social que los produjo y les permitió desempeñarse.

Sin embargo, este tipo de cuestionamiento no se puede sustentar sobre la base de sostener que las Ciencias Sociales en su esencia, ya habían resuelto el problema de la integración teórico/práctica que está implicado en la construcción del conocimiento social, defender que estas eran disciplinas teóricas y aplicadas constituye una falacia teóricoconceptual y metodológica, puesto que éstas en ese momento histórico se caracterizaban en nuestro medio por su indiferencia moral y por la actitud contemplativa que se descendía de los problemas sociales como referentes de acción social, empeñándose por el contrario en la construcción de un estatus y una legitimidad científica. Sin embargo, se afirmaba que los intereses de las demás Ciencias Sociales no estaban en contradicción irreconciliable por la base con los intereses del pueblo colombiano, mientras que este argumento solo aplicaba para el caso de Trabajo Social. ¡Vaya ironía más grande!

\section{Algunas consideraciones sobre el contexto actual}

En general y en las condiciones contemporáneas del contexto actual no se puede esperar que el desarrollo y consolidación del Trabajo Social como profesión-disciplina, vaya a estar determinado exclusivamente por la fundamentación que se imparta en los procesos formativos a partir del conocimiento y comprensión de las teorías aportadas por las Ciencias Sociales y Humanas; eso no es suficiente, porque incluso, algunas de esas epistemologías, hay que tomarlas con reserva crítica, ya que están formuladas en contravía de la tendencia histórica que ha caracterizado el origen y desarrollo del Trabajo Social como profesióndisciplina con una orientación interventiva y una vocación aplicada. Por esta razón, es importante tener muy en cuenta la especificidad o particularidad del desarrollo profesionaldisciplinar, que permita avanzar en la construcción de un conocimiento social, que fundamente la intervención profesional. Sin embargo, se debe tener claro que en el contexto

Prospectiva. Revista de Trabajo Social e intervención social • No. $29 \bullet$ ene.-jun. $2020 \bullet$ pp. 01-38 e-ISSN: 2389-993X • Doi: 10.25100/prts.v0i29.8097

Universidad del Valle - Cali, Colombia 
actual, tenemos que asumir este doble desafío, ya que también es necesario promover y articular una formación académica curricular que al mismo tiempo logre articular la dimensión profesional-disciplinar, con la dimensión inter y transdisciplinaria. En esta perspectiva es importante retomar a Travi (2011) cuando afirma:

\begin{abstract}
Partimos de la hipótesis que el Trabajo Social desde el inicio ha planteado una serie de fundamentos teóricos que orientaron los modos de "comprender" e "intervenir" y que, si bien parte de estas nociones claves aún perduran como base conceptual, se ha producido un proceso de desvalorización, ocultamiento e invisibilización de su proceso de producción. Y si bien, algunos de estos conceptos aún tienen vigencia, hoy (reingresan en América Latina al Trabajo Social), de la mano de autores como Bourdieu, Habermas o Guidens, negando, desconociendo su origen desde el propio campo disciplinar y produciendo un ocultamiento de su producción en un doble proceso que podríamos denominar de "colonización interna" y "epistemicidio disciplinar. (p. 2).
\end{abstract}

Situación ésta que se agrava por el rechazo y el desconocimiento del contexto, en que fueron posibles los antecedentes fundacionales y la fundamentación de esta profesióndisciplina; a este estado de cosas, ha contribuido también la ignorancia muy generalizada por cierto, que existe en el ámbito continental sobre los principales fundamentos y obras de las pioneras o clásicas del Trabajo Social.

En esta perspectiva, es interesante referenciar en el contexto actual de la llamada posreconceptualización la caracterización que formula Malagón (2012) en relación con la existencia de tres tendencias que se vienen expresando en Colombia y América Latina. La primera, se manifiesta en el regreso a una formación profesional neoconservadora, que articula el funcionalismo-estructural con la visión sistémica de primer y segundo orden, pero que además, incorpora las teorías del caos y la complejidad, la terapia familiar y los derechos humanos con la enseñanza de los métodos de caso, grupo y comunidad.

La segunda tendencia busca explicar las diferencias entre profesión y disciplina para justificar e iniciar la formación de trabajadores sociales investigadores, lo cual genera según el autor una serie de obstáculos epistemológicos derivados de este nuevo estatuto epistemológico, que es necesario examinar en profundidad. Este obstáculo se expresa según el autor en los siguientes términos:

El primero reside en la dificultad que existe para diferenciar las formas de pensamiento que dominan lo profesional y lo disciplinar. Dada la mayor tradición de la profesión, tiende a creerse que la investigación disciplinar se resuelve en la investigación diagnóstica o evaluativa que exige la práctica profesional, desconociendo la autonomía y las distancias que existen entre ellas. Con esta idea se concluye que diferenciar lo profesional de lo disciplinar conduce a una escisión equivoca. El segundo obstáculo está relacionado con el análisis complejo que entraña definir el objeto de estudio, o campo disciplinar del Trabajo Social, pues su contenido fue destituido por la Reconceptualización (...) Un obstáculo adicional tiene que ver con el prejuicio todavía existente en algunos ámbitos del Trabajo Social, según el cual el ejercicio disciplinar autónomo tendería a desnaturalizar el carácter "práctico" del Trabajo Social y lo convertiría en una forma de teorización similar a la sociología. (Malagón, 2012, pp. 301$302)$.

Prospectiva. Revista de Trabajo Social e intervención social • No. $29 \bullet$ ene.jun. $2020 \bullet$ pp. 01-38 e-ISSN: 2389-993X • Doi: 10.25100/prts.v0i29.8097

Universidad del Valle - Cali, Colombia 
Estrada-Ospina

La tercera tendencia como lo plantea Malagón (2012) parte de retomar la formación profesional y disciplinar incorporando la teoría crítica y la economía política en el cuestionamiento del estatus quo, es decir, del establecimiento, pero también incluye la crítica del Trabajo Social, para justificar el planteamiento según el cual se puede ser revolucionario no por ser trabajador social sino por la fuerza de un compromiso personal con la utopía de la humanidad.

Con las anteriores hipótesis se puede estar o no de acuerdo, algunas de ellas se pueden poner en cuestión con sólidos argumentos (no es el propósito de este trabajo). Sin embargo, hay que admitir que pueden servir como hipótesis orientadoras de trabajo, pero también sirven para orientar la investigación y la reflexión sobre la historia del Trabajo Social, que permita identificar las tendencias en la formación y también caracterizar la práctica social profesional-disciplinar presente y futura.

El desarrollo profesional y disciplinar del Trabajo Social en Colombia y en el resto de América Latina sólo será posible en la medida en que se logre avanzar sistemáticamente en el siguiente horizonte: 1. Qué la fundamentación y la intervención profesional en la formación se soporte en el dominio y aplicación de unos referentes epistemológicos, ontológicos, teórico-conceptuales, metodológicos, técnico-operativos y ético-políticos. 2. Qué se enfatice en la formación la relación investigación-intervención priorizando los métodos de investigación social aplicada promoviendo la integración metodológica entre los enfoques cualitativo y cuantitativo. 3. Qué se enfatice en la formación la intervención en lo social en teorías, enfoques y metodologías de intervención individual y colectivas más aplicados en el campo profesional-disciplinar. 4. Qué no se ignore en la formación académica la relación de origen e identidad profesional fundacional de nuestra profesióndisciplina, teniendo siempre como eje central el contexto socio-histórico concreto latinoamericano, que permita avanzar en la construcción de un conocimiento social, que contribuya a comprender, interpretar y explicar los problemas, problemáticas y necesidades sociales o humanas. 5 . No se debe descuidar en la formación la relación dinámica que existe entre el contexto micro-social en la que se interviene profesionalmente, con el contexto macro-estructural que condiciona dichos procesos y realidades sociales y culturales, porque los fenómenos sociales son históricamente condicionados y están culturalmente determinados.

Finalmente, hay que concluir esta reflexión adhiriendo a Kruse (1969) cuando afirmaba que la Reconceptualización fue un movimiento que en nuestro caso también rompió el hechizo de nuestra "dorada y plácida adolescencia", lo más importante nos permitió superar el cruce de caminos, o sea, la encrucijada o el dilema en que se encontraba el Trabajo Social en Colombia. En esta perspectiva lo proyectó encontrando nuevos rumbos, pero también lo dimensionó al tener que ir avanzando reflexivamente y críticamente, potenciando los aciertos, pero también superando los errores vividos durante este complejo proceso de construcción profesional-disciplinar, lo cual ha tenido implicaciones positivas, a pesar, incluso, de todas las dificultades existentes en la construcción de este proyecto en nuestro país y en el resto de América Latina, por supuesto con resultados marcados por desarrollos diferenciados y desiguales.

Prospectiva. Revista de Trabajo Social e intervención social • No. $29 \bullet$ ene.jun. $2020 \bullet$ pp. 01-38 e-ISSN: 2389-993X • Doi: 10.25100/prts.v0i29.8097

Universidad del Valle - Cali, Colombia 
En síntesis, el aporte significativo hecho por el programa de Trabajo Social de la Universidad de Caldas a la difusión de las ideas de la Reconceptualización, así como también su contribución en la aplicación del llamado "Método Caldas" en la formación académica pertenece quiérase o no a la historia del Trabajo Social en Colombia.

\section{Referencias bibliográficas}

Barreix, J., y Castillejos, S. (2003). Metodología y método en Trabajo Social. Argentina: Espacio Editorial.

Celats. (1983). Trabajo Social en América Latina. Balance y perspectivas. Lima, Perú: Ediciones Celats.

Corredor, R. (1972). Documento presentado ante el coordinador del comité "Ad-hoc" para la evaluación del programa de Trabajo Social, Facultad de Ciencias Humanas. Manuscrito inédito, Universidad Nacional de Colombia. Bogotá, Colombia.

Claustro de profesores y estudiantes de Trabajo Social de la Universidad Nacional de Colombia. (1972). Documento presentado ante el comité "Ad-hoc" para la evaluación del programa de Trabajo Social, Facultad de Ciencias Humanas. Manuscrito inédito, Universidad Nacional de Colombia. Bogotá, Colombia.

De Robertis, C. (2011). Herman C. Kruse. Un reconceptualizador del Servicio Social. España: Editorial Lumen Hvmanitas.

Estrada, V. (1974). Dependencia, universidad y la reconceptualización del Trabajo Social (Tesis de pregrado). Universidad de Caldas. Facultad de Ciencias y Humanidades. Departamento de Trabajo Social. Manizales, Colombia.

Eroles, C. (Coord.). (2005). Glosario de temas fundamentales en Trabajo Social. Buenos Aires: Espacio Editorial.

Faleiros, V. (1971). Ciencia y Servicio Social. En Seminario Latinoamericano de Trabajo Social. Instituto de Solidaridad Internacional (ISI). Ambato-Ecuador.

Faleiros, V. (2003). Estrategias de empowerment en Trabajo Social. Buenos Aires-México: Grupo Editorial LumenHvmanitas.

Furtado, C. (1969). Dialéctica del Desarrollo. México: Fondo de Cultura Económica.

Gunder-Frank, A. (1967). Capitalismo y Subdesarrollo en América Latina. México: Siglo veintiuno editores.

Gunder-Frank, A. (1973). América Latina: Subdesarrollo o Revolución. México: Ediciones Era.

Kruse, H. (1969). El servicio social en la encrucijada. Hoy en el Servicio Social, (16-17).

Kruse, H. (1971). La reconceptualización en América Latina. Revista Selecciones de Servicio Social, (13).

Lima, B. (1975). Epistemología del Trabajo Social. Buenos Aires: Editorial Hvmanitas.

Malagón, E. (2012). Fundamentos de Trabajo Social. Bogotá: Universidad Nacional de Colombia.

Martínez, M. (1981). Historia del Trabajo Social en Colombia 1970-1975. Bogotá: Tecnilibros.

Miranda, M. (2003). Pragmatismo, interaccionismo simbólico y Trabajo Social. De cómo la caridad y la filantropía se hicieron científicas (Tesis de doctorado). Universitat Rovira I Virgili. Departament d' Antrpology, Filosofía y Treball Social. Tarragona, España.

Morales, H. (1971). Metodología del Trabajo Social para la acción transformadora. Manizales: Universidad de Caldas.

Presidencia de la República de Colombia. (30 de mayo de 1964). [Decreto 1297 de 1964]. DO: 31404.

Prospectiva. Revista de Trabajo Social e intervención social • No. $29 \bullet$ ene.jun. $2020 \bullet$ pp. 01-38 e-ISSN: 2389-993X • Doi: 10.25100/prts.v0i29.8097

Universidad del Valle - Cali, Colombia 
Quintero, S. (2018). Contexto, tendencias y actores de la Reconceptualización. Revista Eleuthera, 20, 179-198. doi: 10.17151/eleu.2019.20.10.

Travi, B. (2010). Construcción de la identidad, historia y formación profesional. En V. Ibáñez (Comp.), Historia, identidad e intervención profesional. Argentina: Ediciones Suárez.

Travi, B. (2011). Conceptos e ideas clave en la obra de Mary Ellen Richmond y la vigencia actual de su pensamiento. Cuadernos de Trabajo Social, 24, 57-67.

Torres, J. (1988). Historia del Trabajo Social. Bogotá: Plaza \& Janes Editores.

Torres, L. (2005). Reflexiones en torno al movimiento de Reconceptualización. En N. Alayón (Org.), Trabajo Social Latinoamericano. A 40 años de la Reconceptualización (pp. 103-113). Buenos Aires, Argentina: Espacio Editorial.

Torres, L. P., Rincón, M. T., Giraldo, C. L., Ospina, A. M., Maldonado, M. C, Estrada, V. M... Carvajal, A. (2005). Historia de la Escuela de trabajo Social y Desarrollo Humano de la Universidad del Valle 1953-2003: cincuenta años aportando al desarrollo de la región. Colombia: Universidad del Valle. Facultad de Humanidades.

Uricoechea, F. (1999). La profesionalización académica en Colombia. Bogotá: Tercer mundo Editores-IEPRI.

Zuleta, E. (1999). Acerca de la naturaleza de las ciencias sociales. Bogotá: Ediciones Contravía. 


\section{OTROS ARTÍCULOS DE PROSPECTIVA No. 29 DE 2020}

EDITORIAL

La Reconceptualización: una opción a la encrucijada del Trabajo Social en Colombia Víctor Mario Estrada-Ospina

\section{ARTÍCULOS}

Formación profesional y la práctica supervisada en el Servicio Social brasileño

Reginaldo Ghiraldelli

El rol docente del tutor y supervisor de prácticas de Trabajo Social: construcción de la reflexividad y el compromiso durante la formación a través de la supervisión

Carmina Puig-Cruells

Problematizando las prácticas preprofesionales en Trabajo Social. Desafios y perspectivas

Ruth Noemí Parola

Trabajo Social en contextos de formación política: la práctica transformadora

Angélica López-Yepes

Jackeline Cuenca-Echeverry

Investigación cuantitativa en una práctica universitaria de intervención en comunidad en el norte de México

Adán Cano-Aguilar
Interventores y comunidades vulnerables: una propuesta de formación para universitarios

Dulce Nayeli Cohetero-Hernández

Fidel González-Quiñones

Reagrupación familiar de menores en Aragón. Propuestas de acompañamiento en el proceso migratorio

Chabier Gimeno-Monterde

José David Gutiérrez-Sánchez

Aportaciones de la Educación en Derechos Humanos (EDH) y la Investigación Acción Participativa (IAP) en contextos de trabajo comunitario

Carla Cubillos-Vega

Condiciones para una NeoReconceptualización del Trabajo Social en Chile, Latinoamérica y el Caribe

Luis Vivero-Arriagada

Justicia sin daño: una apuesta por el fortalecimiento del acceso a la justicia Diego Fernando Acosta-Daza

\section{IN MEMORIAM}

Camilo Bautista Ochoa, un santandereano que se enamoró del Pacífico

Jesús Glay Mejía-Naranjo

\section{PROSPECTIVA}

Revista de Trabajo Social e Intervención Social 